\title{
Recent Chemical Methodology Advances in the Total Synthesis of Meroterpenoids
}

\author{
Jan Petrovčič, ${ }^{2}$ Chad Nicholas Ungarean ${ }^{2}$ and David Sarlah ${ }^{1,2,}$ \\ ${ }^{1}$ Roger Adams Laboratory, Department of Chemistry, University of Illinois at Urbana-Champaign, \\ 600 S Mathews Avenue, Champaign, IL 61801, USA \\ ${ }^{2}$ Dipartimento di Chimica Organica, Universita' di Pavia, Via Taramelli 12, 27100 Pavia, Italy \\ *Corresponding author: E-mail: sarlah@illinois.edu, \\ Tel.: (217) 244-9154
}

Received: 05-07-2021

\begin{abstract}
Heterogeneity of meroterpenoids arising from their dual biosynthetic origins is constantly provoking synthetic chemists to utilize their ingenuity and revise their retrosynthetic logic. By studying recent publications on meroterpenoid synthesis, tremendous advances in the field of synthetic organic chemistry can be witnessed. This feature article covers some of the most intriguing total syntheses and synthetic studies towards the meroterpenoid class of natural products from the last five years.
\end{abstract}

Keywords: Meroterpenoids, total synthesis, natural products, tactics, strategies

\section{Introduction}

Meroterpenoids represent a family of natural products that originate from the combination of the Greek word meros, meaning part, and terpenoids, which are natural isoprene-derived compounds. Their structural diversity stems from their hybrid terpenoid and polyketide biosynthetic roots. Numerous new meroterpenoids are isolated each year from natural sources, which requires the employment and advancement of modern synthetic organic chemistry to effectively obtain sufficient quantities of newly isolated meroterpenoids for more detailed studies. The purpose of this review is to highlight the most efficient modern chemical tools and strategies that have been developed to access different classes of meroterpenoids since 2015. Supplemental and complementary to this work is a vast array of literature covering various aspects of meroterpenoid chemistry. For example, isolation and structure elucidation of fungal meroterpenoids has been reviewed by Geris. ${ }^{1}$ The work of $\mathrm{Abe}^{2}$ describes their biosynthetic origins and work of $\mathrm{Kijjoa}^{3}$ focuses on their biological properties. A more specific review on biosynthesis as well as chemical synthesis of fungal meroterpenoids breviones has been published by Macías. ${ }^{4}$ Additionally, a conceptionally similar survey on meroterpenoids from Streptomyces bacteria has been disclosed earlier this year jointly by Moore and George. ${ }^{5}$ In contrast, other reviews focus exclusively on synthetic efforts toward specific classes of meroterpenoids. Reviews by Ōmura ${ }^{6}$ and Gordaliza ${ }^{7}$ cover $\alpha$-pyrone and quinone/hydroquinone containing meroterpenoids, respectively. Due to the fascination of chemists with certain meroterpenoids like hyperforin (from polyprenylated acylphloroglucinol - PPAP - class), several total syntheses have been published and thoroughly reviewed by Richard. ${ }^{8}$ Therefore, the aforementioned topics will be omitted from this feature article.

\section{1. George's Total Syntheses of Hyperjapones} (2016)

Meroterpenoids hyperjapones A-E (1-5), isolated form Hypericum japonicum, were prepared in three steps by George's group in 2016 (Schemes 1 and 2). ${ }^{9}$ Through subsequent derivatizations they were also able to access to hyperjaponols A (6) and C (7) as well as two other meroterpenoids that have yet to be isolated from natural sources. The synthesis commenced from phloroglucinol (8), which was acylated under classical Friedel-Crafts conditions with isobutyryl chloride to furnish ketone 9. This material was dearomatized through trimethylation with 


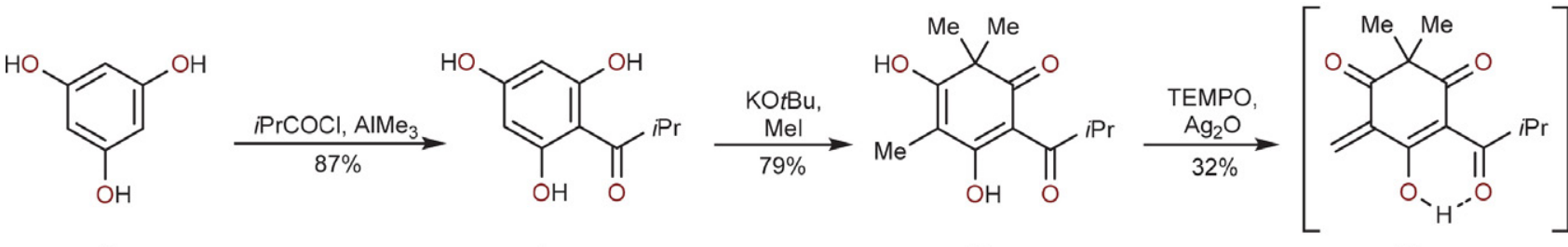

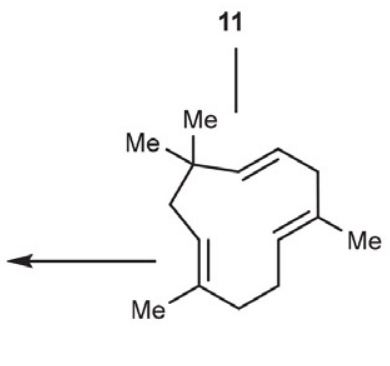

$\alpha$-humulene (12)<smiles>N#CC(C#N)=C(C#N)C#N</smiles><smiles>C=C(CC[C@@]1(C)CC2=C(C(C)(C)C(=O)C(=CO)C(=O)C(C)C)O[C@]1(C)C/C=C/C(C)(C)C[C@@H]2O)C(C)C</smiles>

(士)-hyperjaponol A (6)

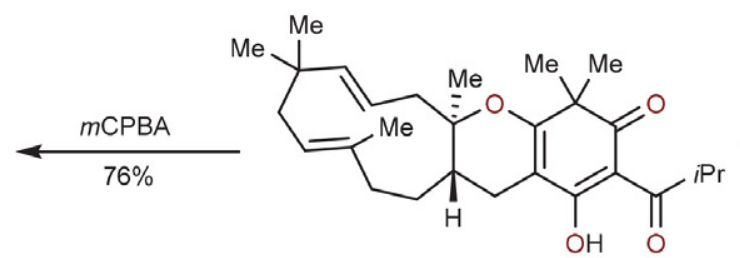

( \pm )-hyperjapone A (1)<smiles>C=C(C)C1C[C@H](O)[C@]2(C)CC[C@H]3CC4=C(O[C@]3(C)C[C@H]12)C(O)=C(C(=O)C(C)C)C(=O)C4(C)C</smiles>

(士)-hyperjaponol C (7)

Scheme 1. George's biomimetic total syntheses of ( \pm )-hyperjapone A (1), ( \pm )-hyperjaponols A (6) and C (7). $m$ CPBA = meta-chloroperoxybenzoic acid. TEMPO $=(2,2,6,6$-tetramethylpiperidin-1-yl $)$ oxyl.<smiles>CC1=C(O)C(C)(C)C(=O)C(C(=O)C(C)C)=C1O</smiles>

9

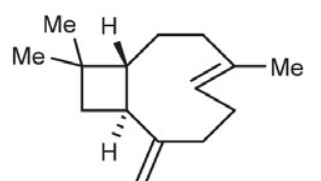

caryophyllene (14),

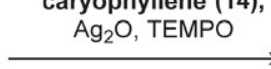<smiles>CC(C)C(=O)C1=C(O)C2=C(O[C@]3(C)CC[C@H]4CC(C)(C)[C@H]4CCC[C@H]2C3)C(C)(C)C1=O</smiles>

hyperjapone B (2)<smiles>CC(C)C(=O)C1=C(O)C2=C3O[C@](C)(CC[C@@H]4C[C@H]2CCC[C@H]4C1(C)C)C(=O)C3(C)C</smiles>

$60 \%, 2.5: 1$<smiles>CCC(C)C(=O)C1=C(O)C(C)=C(O)C(C)(C)C1=O</smiles>

15<smiles>CCC(C)C(=O)C1=C(O)C2=C(C(C)(C)C)O[C@]3(C)CC[C@@H]4C[C@H]2CCC[C@@H]4C(C)(C)C[C@H]13</smiles>

hyperjapone C (3)<smiles></smiles>

$61 \%, 2.5: 1$

hyperjapone E (5) methyl iodide to 10; subsequent oxidation with TEMPO and $\mathrm{Ag}_{2} \mathrm{O}$ lead to in situ formation of reactive quinone methide 11, which reacted with $\alpha$-humulene (12) in the same pot to arrive at racemic hyperjapone A (1). This natural compound was divergently taken forward: diastereoselective epoxidation of the trisubstituted olefin with $m \mathrm{CPBA}$ followed by treatment of the isolable epoxide $\mathbf{1 3}$ with ei- ther tetracyanoethylene $\pi$-Lewis acid or $p$-toluenesulfonic Brønsted acid gave racemic hyperjaponols A (6) and C (7), respectively.

In addition to humulene (12), caryophyllene (14) was also a competent substrate for the hetero-Diels-Alder key step, ultimately providing a 2.5:1 mixture of hyperjapones B (2) and D (4) (Scheme 2). Notably, the same ra- 


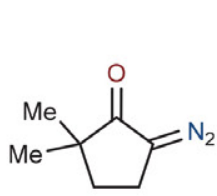

17

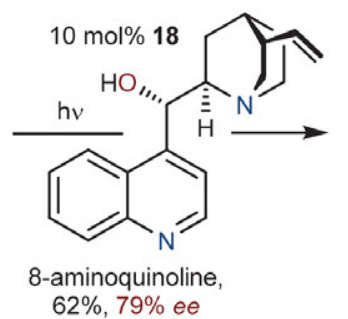<smiles>CC(=O)C1CCC1(C)C</smiles>

19<smiles>Nc1cccc2cccnc12</smiles><smiles>CCC1(C)CC(C2=CC3(CCC2)OCCO3)C1C(=O)Nc1cccc2cccnc12</smiles>

$\mathrm{Ag}_{2} \mathrm{CO}_{3}, 72 \%$

$(1) \mathrm{Cp}_{2} \mathrm{Zr}(\mathrm{H}) \mathrm{Cl}$
$(2) \mathrm{KOH}, \mathrm{MeOH}$,
$70 \%$ over 2 steps

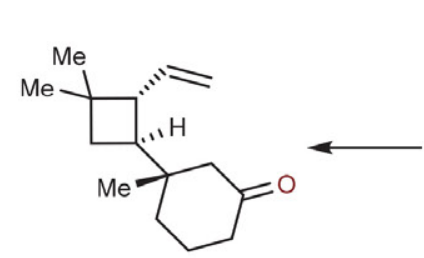

24

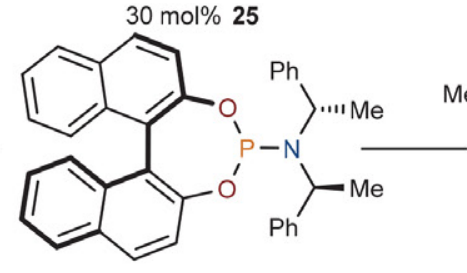

$15 \mathrm{~mol} \% \mathrm{CuTC}$, $\mathrm{AlMe}_{3}, 94 \%, 19: 1 d r$

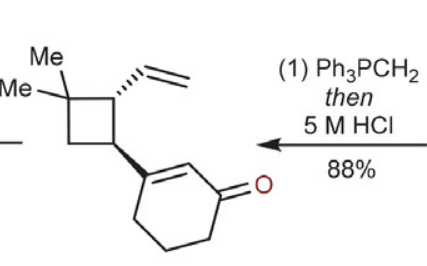

23<smiles>CC1(C)CC(C2=CC3(CCC2)OCCO3)[C@H]1C=O</smiles>

22<smiles>C=CC1[C@H](C2(C)CCC(=Cc3c(Br)cc(OC)cc3OC)C(=O)C2)[C@H](C=C)C1(C)C</smiles>

26

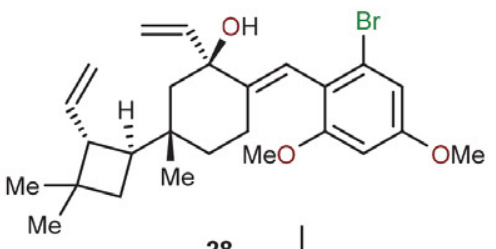

28

10 mol\% HG-II, 1,4-BQ, $93 \%$

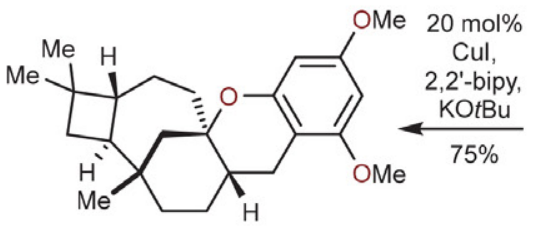

31

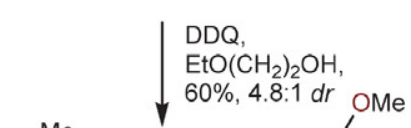

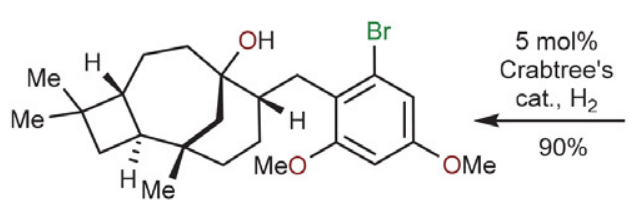

30

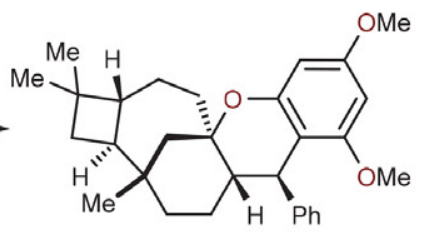

33

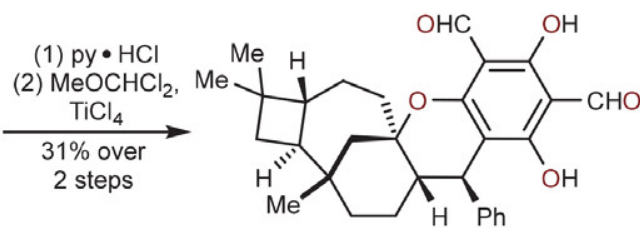

(+)-psiguadial B (16)

Scheme 3: Reisman's enantioselective total synthesis of (+)-psiguadial B (16). 2,2'-bipy =2,2'-bipyridine. Cp $=$ cyclopentadienyl. DDQ $=2,3$-dichloro-5,6-dicyano-1,4-benzoquinone. $\mathrm{HG}=$ Hoveyda-Grubbs. py = pyridine. $\mathrm{TC}=$ thiophene-2-carboxylate.

tio of hyperjapones C (3) and E (5) was obtained when 15, derived from $S$-2-methybutyric acid chloride, was reacted with caryophyllene (14) in the presence of TEMPO and $\mathrm{Ag}_{2} \mathrm{O}$. The authors attributed the observed product ratios to a 3:1 thermodynamic distribution of $\beta \alpha$ and $\beta \beta$ caryophyllene conformers present in solution.

\section{2. Riesman's Total Synthesis of (+)-Psiguadial B (2016)}

Plant extracts used in traditional medicine contain a myriad of biologically active compounds with Psidium guajava following suit accordingly. Among other compounds, 
<smiles>O=Cc1c(O)cc(O)c(C=O)c1O</smiles>

34

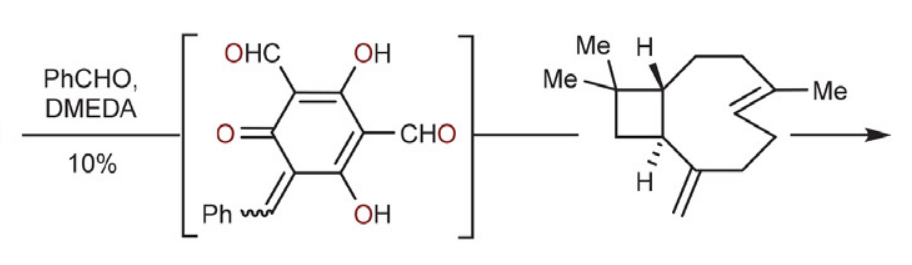

35 caryophyllene (14)

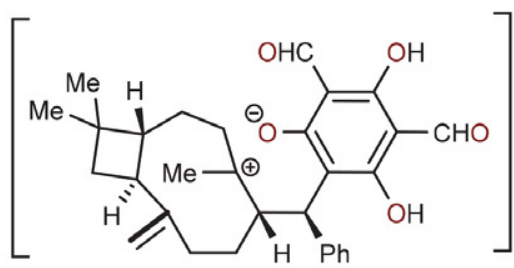

36

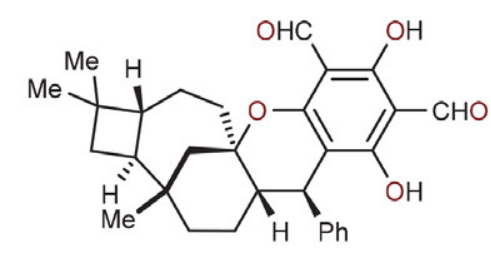

psiguadial B (16)

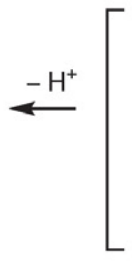

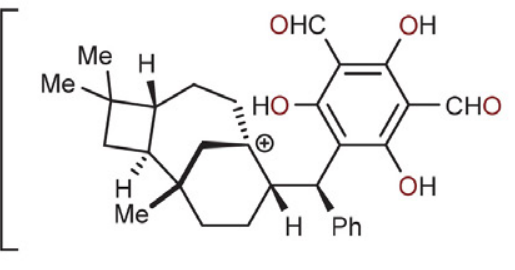

38

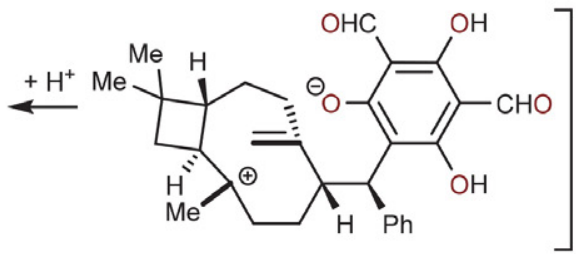

37

Scheme 4: Cramer's biomimetic total synthesis of pisguadial B (16). DMEDA $=N, N^{\prime}$-dimethylethylenediamine

the meroterpenoid psiguadial B (16) was also produced, which was prepared for the first time in its enantiopure form by Reisman's group in 2016 (Scheme 3). ${ }^{10}$ To begin the synthesis, the authors recognized a-diazo-2,2-dimethylcylopentanone (17) as a starting point. It served as a suitable material for the first key step of a photochemical Wolff rearrangement followed by asymmetric ketene trapping. Stereochemical outcome of this transformation with 8 -aminoquinoline nucleophile was governed by a chiral (+)-cinchonine (18) catalyst. Thereafter, a second key step - palladium catalyzed $\mathrm{C}\left(\mathrm{sp}^{3}\right)-\mathrm{H}$ alkenylation of intermediate 19 - was executed with 3-iodocyclohex-2-en-1-one derived vinyl iodide $\mathbf{2 0}$ as a partner, which provided the cis-decorated cyclobutene $\mathbf{2 1}$. The amide directing group was then transformed to the cis-aldehyde (not shown) under reductive conditions with $\mathrm{Cp}_{2} \mathrm{Zr}(\mathrm{H}) \mathrm{Cl}$, which was isomerized to the thermodynamically more stable trans-aldehyde 22 under basic conditions. The addition of methylene triphenylphosphorane to 22 effectively installed the pendant vinyl group, and subsequent ketal deprotection yielded enone 23. The quaternary stereocenter in $\mathbf{2 4}$ was formed with high levels of diastereoselectivity using conjugate addition. A combination of trimethyl aluminum, catalytic amounts of copper thiophene carboxylate and chiral phosphoramidite ligand $\mathbf{2 5}$ were invaluable for its success. Conjugated enone $\mathbf{2 6}$ was constructed via an intermolecular aldol condensation with aromatic aldehyde 27, and direct 1,2-addition of vinyl lithium gave rise to tertiary allylic alcohol 28. The latter underwent a subsequent ring closing metathesis catalyzed by Hoveyda-Grubbs second-generation catalyst. Reduction of the two olefins in 29 and consequential installation of an additional stereocenter was accomplished by hydrogenation using Crabtree's catalyst. Tertiary alcohol and aryl bromide moieties in intermediate 30 participated in an intramolecular, copper-catalyzed
$O$-arylation reaction. Benzylic oxidation of $\mathbf{3 1}$ and subsequent reaction with ethoxy ethanol gave 32, which reacted with higher-order cuprate $\mathrm{Ph}_{2} \mathrm{Cu}(\mathrm{CN}) \mathrm{Li}_{2}$ in the presence of boron trifluoride etherate to yield 33. Ultimately, pyridinium hydrochloride mediated demethylation to the penultimate material, which then underwent Rieche formylation, completed the total synthesis of (+)-psiguadial B (16).

\section{3. Cramer's Total Synthesis of Psiguadial B (2017)}

In the year following Reisman's landmark psiguadial B total synthesis, a second total synthesis was disclosed by Cramer's group in which they accomplished a biomimetic, one-pot synthesis (Scheme 4$).{ }^{11}$ In a remarkable reaction cascade, they merged commercially available caryophyllene (14), benzaldehyde and bisformylphloroglucinol (34) fragments to obtain gram quantities of the desired product. Their approach differs from that of Reisman's in the early introduction of two formyl moieties on the arene portion of the cycloaddition partner. Careful reaction optimization revealed that $N, N^{\prime}$-dimethylaminoethane (DMEDA) in polar yet weakly nucleophilic HFIP sufficiently promoted the anticipated ionic pathway. A clever ozonolysis workup allowed for a simple recrystallization as the only purification needed in the sequence. Ozone selectively oxidized exocyclic double bonds of side products originating from undesired hetero-Diels-Alder reactivity between ortho-quinone methide 35 and the trisubstituted olefin in 14. Additionally, calculations provided an insight into the intriguing mechanism of the aforementioned ionic cascade: it is proposed that initially formed mixture of ortho-quinone methides 35 undergoes Michael addition with caryophyllene (14). Proton transfer of tertiary carbocation 36 into intermediate 37 enabled a cationic cycliza- 
tion to give 38. The final six-membered ring of the natural product was forged by an intramolecular phenol trapping.

\section{4. Maimone's Total Synthesis of Berkeleyone A (2016)}

Isolated from extremophilic fungi of the infamous Berkeley Pit lake, berkeleyone A (39) is a meroterpenoid with a highly decorated bicyclo[3.3.1]nonane core. Besides its appealing structure, interest in this compound stems from its caspase- 1 inhibitory activity as well as its potential to serve as a lead compound for further structure-function studies. To date, two groups have undertaken and completed this formidable synthetic challenge, both in 13 steps and racemic fashion.

The first synthesis of berkeleyone A (39) was completed by Maimone's group (Scheme 5). ${ }^{12}$ Farnesyl bromide (40) was selected as a commercially available starting material, and was used for $C$-alkylation of propionitrile anion. The terminal alkene in alkylated propionitrile (not shown) was then epoxidized via a two-step, one-pot bromohydrin formation and subsequent oxirane closing. Treatment of epoxide $\mathbf{4 1}$ with titanocene dichloride and zinc triggered a radical polyene cyclization with the nitrile terminating group. The former transformed to an imine which was hydrolyzed during following workup. Secondary alcohol from epoxide opening was silylated with TB-
$\mathrm{SCl}$ and imidazole. A higher oxidation state variation of the Robinson annulation reaction was performed on the lithium enolate of $\mathbf{4 2}$ with diketene to forge the final requisite six-membered ring, notably with high levels of diastereoselectivity. This key step is a testimony to the practicality of the aforementioned methodology that was developed by the same group for the total synthesis of hyperforin. ${ }^{13}$ The 1,3-diketone motif in $\mathbf{4 3}$ was then chemoselectively O-methylated using TMS-diazomethane, and subsequent oxidative ring expansion was induced with PIDA under basic conditions to furnish the core (44) of berkeleyone A. Olefination under classical Wittig conditions was followed by chlorination with LiTMP and TsCl. A challenging bridgehead deprotonation with LiTMP enabled acylation with methyl chloroformate. The installed chlorine in $\mathbf{4 5}$ was leveraged for Suzuki coupling to introduce the methyl group with silyl deprotection yielding 46 . Krapcho-type demethylation in the presence of a methyl ester gave the penultimate precursor 47 to berkeleyone A, which was immediately oxidized with $m \mathrm{CPBA}$ to furnish the desired natural product.

\subsection{Newhouse's Total Synthesis of Berkeleyone A (2017)}

The Newhouse group took a similar polyene cyclization approach for construction of berkeleyone A (39)

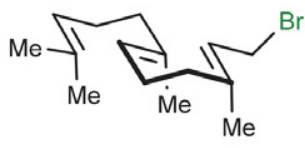

40

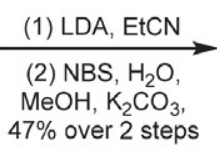

$47 \%$ over 2 steps
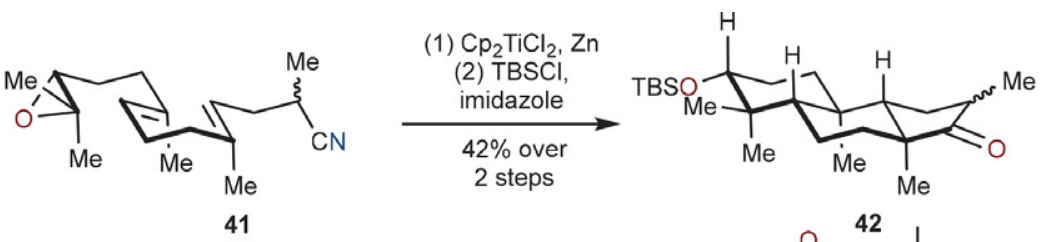

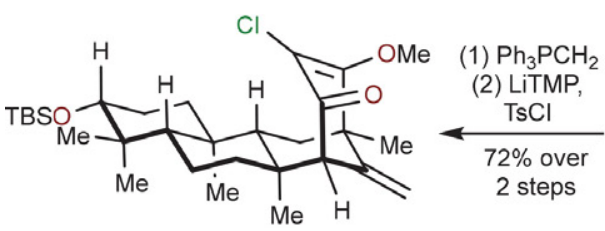

45

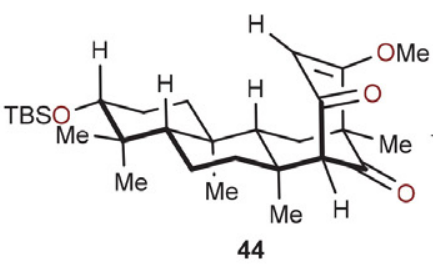

44

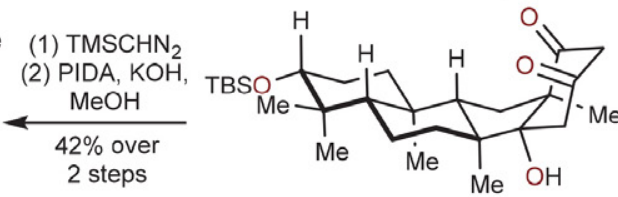

43

(1) $\mathrm{LDA}, \mathrm{ClCO}_{2} \mathrm{Me}$

(2) $\mathrm{MeB}(\mathrm{OH})_{2}, \mathrm{~K}_{3} \mathrm{PO}_{4}, \mathrm{Pd}(\mathrm{OAc})_{2}$, SPhos

(3) $\mathrm{TsOH}, \mathrm{MeOH}, 43 \%$ over 3 steps

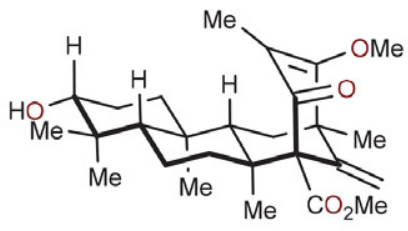

46

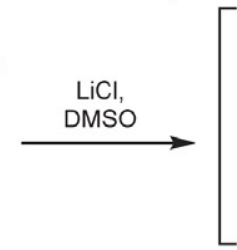

[

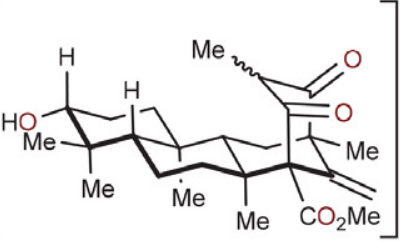

47 over
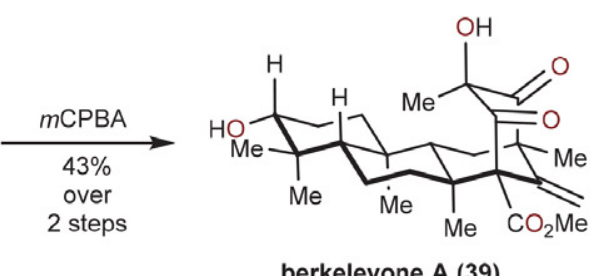

berkeleyone $\mathrm{A}(39)$

Scheme 5: Maimone's total synthesis of berkeleyone A (39). $\mathrm{Cp}=$ cyclopentadienyl. DMSO = dimethylsulfoxide. LDA = lithium diisopropylamide. $m \mathrm{CPBA}=$ meta-chloroperoxybenzoic acid. NBS $=N$-bromosuccinimide. PIDA $=$ phenyliodine(III) diacetate. Sphos $=2$-dicyclohexylphosphino-2',6'-dimethoxybiphenyl. TBS = tert-butyldimethylsilyl. TMP = tetramethylpiperidide. TMS = trimethylsilyl. Ts $=$ tosyl. 


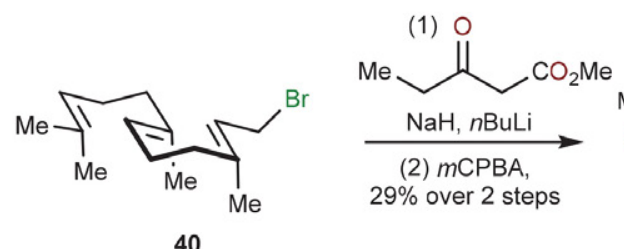

40

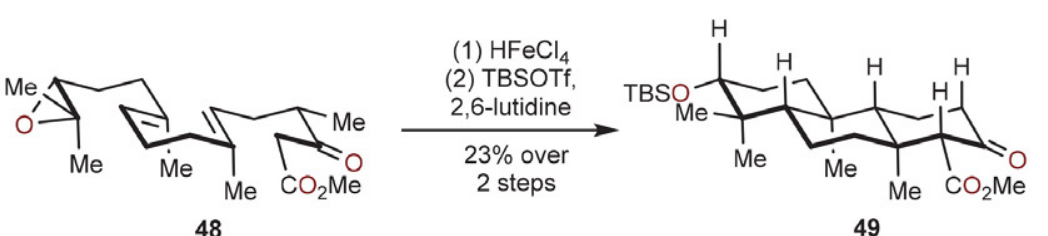

48

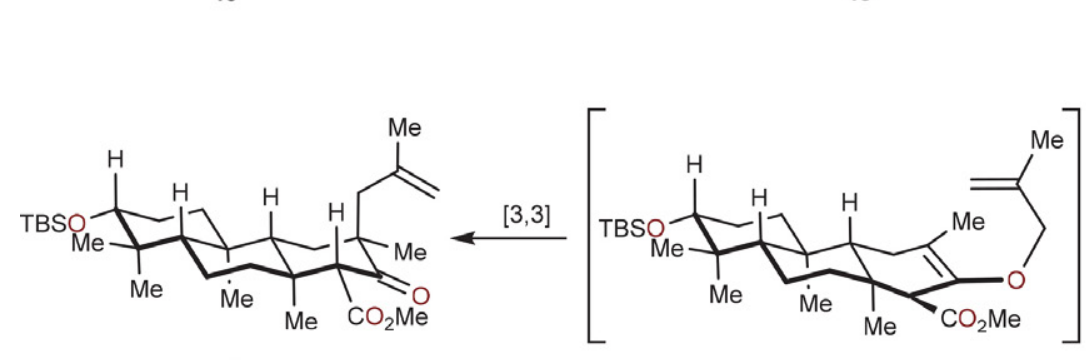

52

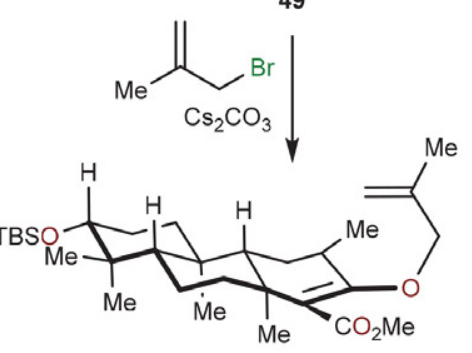

50 $\downarrow \begin{aligned} & \mathrm{Mn}(\mathrm{OAc})_{3}, \\ & 44 \% \text { over } 3 \text { steps }\end{aligned}$

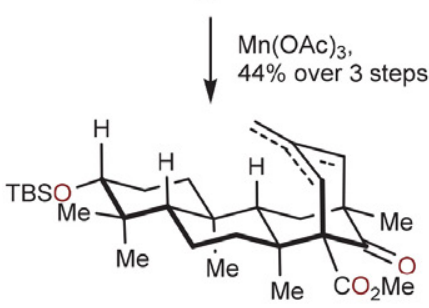

53

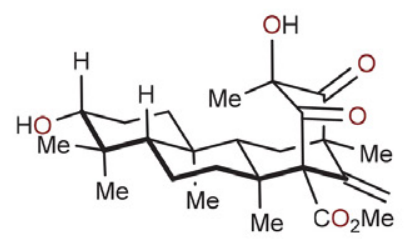

berkeleyone A (39)

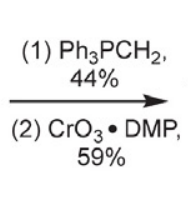

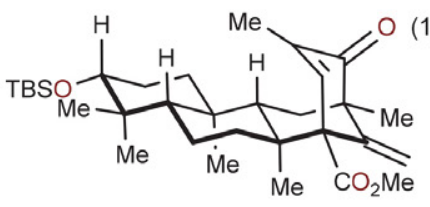

54

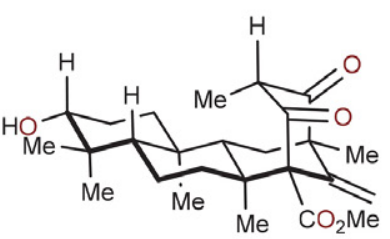

47

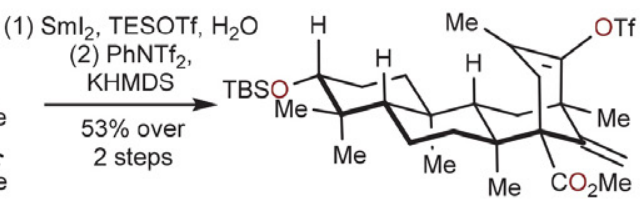

55

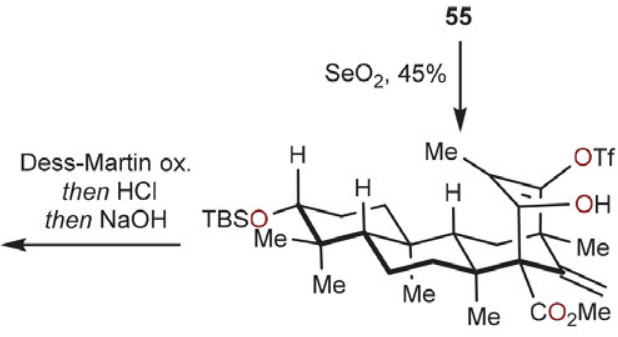

56

Scheme 6: Newhouse's total synthesis of berkeleyone A (39). Ac = acetyl. DMP = 3,5-dimethylpyrazole. $m$ CPBA = meta-chloroperoxybenzoic acid. TBS = tert-butyldimethylsilyl. Tf = triflyl.

(Scheme 6). ${ }^{14}$ Their synthetic sequence also commenced with farnesyl bromide (40), which was used to alkylate methyl 3-oxopentanoate dianion. Chemoselective epoxidation using $m \mathrm{CPBA}$ in the presence of two other trisubstituted alkenes and $\beta$-ketoester moiety yielded terminal epoxide 48. Using this compound, they showcased the first example of epoxide initiated, $\beta$-ketoester terminated, polar polyene cyclization with $\mathrm{HFeCl}_{4}$ acting as a Brønsted acid. The cyclized product 49 was treated with 3-bromo-2-methylpropene in the presence of cesium carbonate. Acetic acid solution of $O$-allylated 50 was heated to $120^{\circ} \mathrm{C}$. [3,3]-Claisen rearrangement of intermediate 51 with transposed exocyclic double bond provided the key $C$-allylated intermediate $\mathbf{5 2}$ for the manganese-mediated SET oxidation and subsequent radical cyclization onto the pendant 1,1-disubstituted double bond. The mixture of alkene isomers 53 (unified structure shown) reacted with methylene triphenylphosphorane in a Wittig olefination reaction. Allylic oxidation of the newly formed endocyclic methylene groups was achieved using Corey's procedure with chromium trioxide 3,5-dimethylpyrazole complex $\left(\mathrm{CrO}_{3} \cdot \mathrm{DMP}\right)$. The resulting enone $\mathbf{5 4}$ was reduced in a 1,4-fashion using $\mathrm{SmI}_{2}$ and in situ formed triflic acid, which is a complementary approach to more traditional methodologies. The authors demonstrated the feasibility of allylic oxidation of vinyl triflates, as $\mathbf{5 5}$ was successfully oxidized to 56. The 1,3-diketone moiety in 47 was revealed following Dess-Martin periodinane (DMP) oxidation and hydrolysis of the vinyl triflate. Oxidation of 47 with $m \mathrm{CP}$ $\mathrm{BA}$ completed the total synthesis of berkeleyone A (39).

\section{6. Newhouse's and Maimone's Syntheses of Terretonin L and Andrastin D (2017)}

Having individually completed the total syntheses of berkeleyone A (39), the Newhouse and Maimone groups collaborated to further explore the chemistry of natural products containing the berkeleyone framework. Their goal was to access members of the andrastin and terretonin classes of meroterpenoids (Scheme 7). ${ }^{15}$ They envi- 
sioned that carbocation $\mathbf{5 7}$ would serve as a key intermediate and would give rise to the andrastin and terretonin skeletons. Experimentally, it was shown that the carbocation $\mathbf{5 7}$ had to be generated from $\mathbf{5 8}$ via oxidation of the corresponding tertiary radical 59. Simple protonation of exocyclic double bond with various Brønsted acids was not feasible for achieving the same goal. Starting from the antepenultimate intermediate $\mathbf{4 6}$ (used in Maimone's synthesis of berkeleyone A) PCC oxidation gave compound 58. This key intermediate required oxidation to arrive at the aforementioned carbocationic species. Inspiration for this transformation came from an alkene hydroalkoxylation methodology developed by Shigehisa. It allows for a variety of unactivated mono-, di- and trisubstituted alkenes to be hydroalkoxylated with primary, secondary, tertiary, or benzylic alcohols in a Markovnikov fashion. ${ }^{16}$ Gratifyingly, treatment with catalytic cobalt(II) salen-type complex 59 and phenylsilane in the presence of
$\mathrm{N}$-fluoro-2,4,6-trimethylpyridinium tetrafluoroborate (60) formed the desired intermediate 57 in situ, which rearranged to 61. Subsequent Krapcho-type demethylation gave racemic andrastin $\mathrm{D}(62)$.

While 63 could be observed in reaction mixtures during the optimization of transformation from $\mathbf{5 8}$ to $\mathbf{6 1}$, further screening was required to favor its formation. This observation is consistent with computational results indicating the exocyclic alkene to be less thermodynamically favored in comparison with the endocyclic isomer. Stemming from Carreira's work with radical hydrochlorination, employment of tosyl chloride proved to be crucial in altering the selectivity towards $63 .{ }^{17}$ After the in situ formation of the same radical $\mathbf{5 9}$ and a homoallyl-type rearrangement, hydrogen atom abstraction from the more sterically accessible methyl group gave rise to 63. Subsequent Krapcho-type demethylation and magnesium monoperoxyphthalate (MMPP) oxidation yielded the penultimate pre-

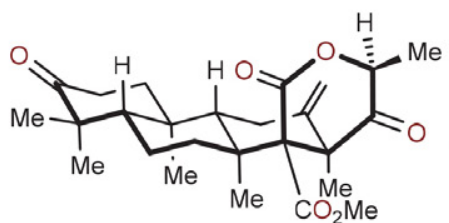

(士)-terretonin L (65)

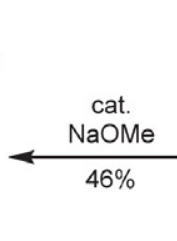

$6 \%$

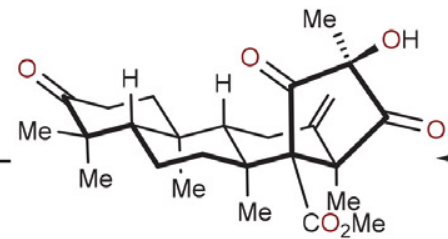

64

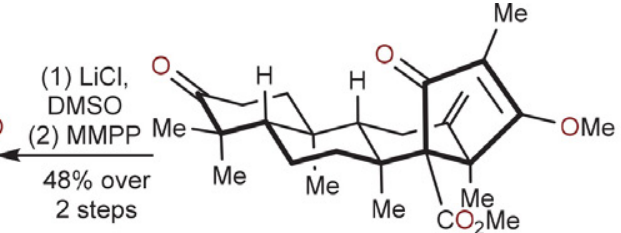

63

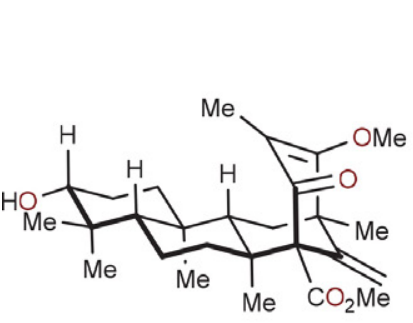

46

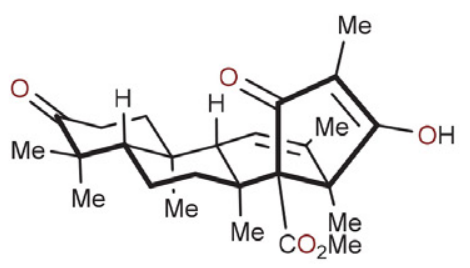

(士)-andrastin D (62)

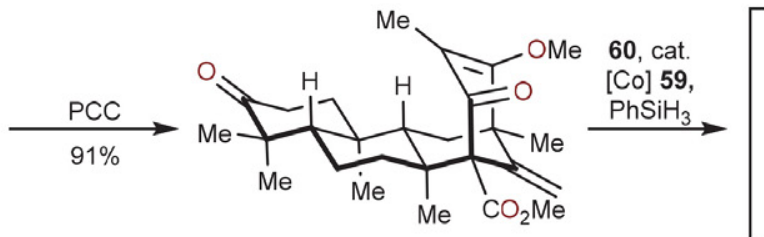

58
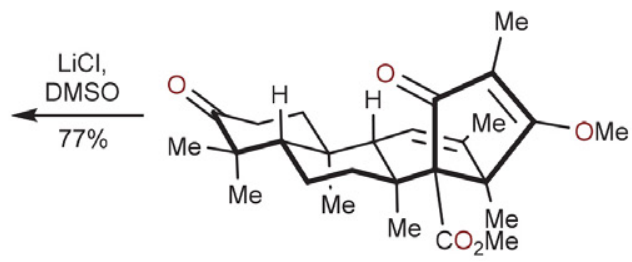

61

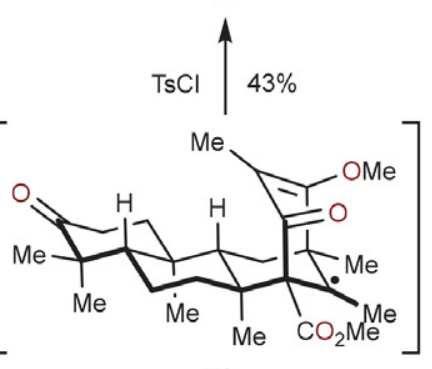

59

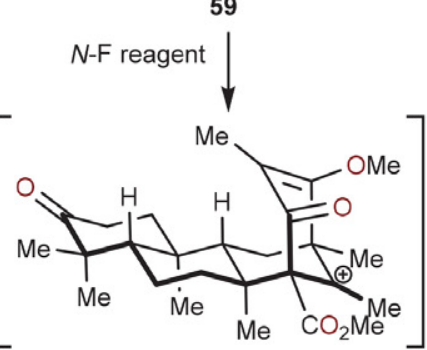

57

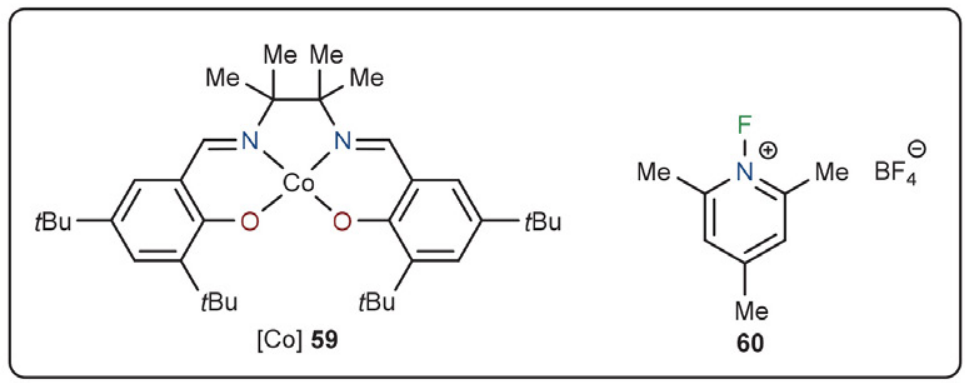

Scheme 7: Newhouse's and Maimone's racemic total syntheses of terretonin L (65) and andrastin D (62). DMSO = dimethyl sulfoxide. MMPP = magnesium monoperoxyphthalate. $\mathrm{PCC}=$ pyridinium chlorochromate $(\mathrm{VI})$.

Petrovčič et al.: Recent Chemical Methodology Advances in the ... 
<smiles>COC1=CC(C)(C)CC(OC(C)(C)C)=C1</smiles>

66<smiles>COC(=O)c1cc(O)cc(O)c1C=[18O]</smiles>

67<smiles>COC(=O)c1cc(OC)cc(O)c1C(=O)OC</smiles>

68

3,4-DMBNH ${ }_{2}$, $\mathrm{AlMe}_{3}, 58 \%$<smiles>COc1cc2c(c(OC)c1I)CN(OC(C)(C)C)C2=O</smiles>

71<smiles>[H][R16]([H])([H])ON1Cc2cc(OC)c(I)c(O)c2C1=O</smiles>

70<smiles>CC1(C)C(=O)CCC[C@H]1O</smiles>

73<smiles>C=CC1=CCC[C@H](OCc2ccccc2)C1(C)C</smiles><smiles>CC1CC=C2[C@@H](CC[C@@H](O)C2(C)C)C1(C)CO</smiles>

79

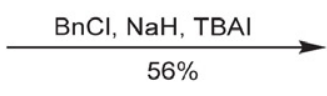<smiles>CC1(C)C(=O)CCC[C@@H]1O[Ga]c1ccccc1</smiles>

74

PhNTf
LHMDS,

$80 \%$

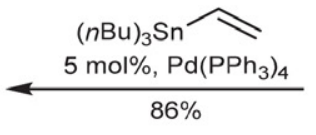

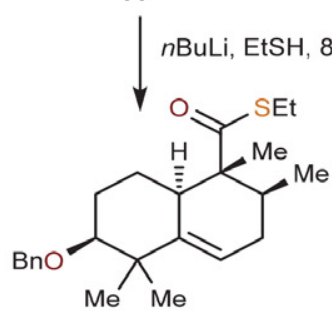

78

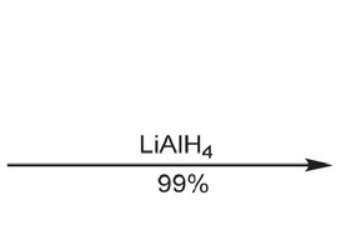

(2)

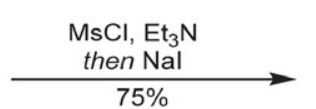<smiles>CC1CC=C2[C@@H](CC[C@@H](O)C2(C)C)C1(C)CI</smiles>

$n \mathrm{BuLi}, \mathrm{ZnCl}_{2}$, then $\mathbf{7 1}$

80

20 mol\% PdSPhos, 20 mol\% SPhos, 56\%

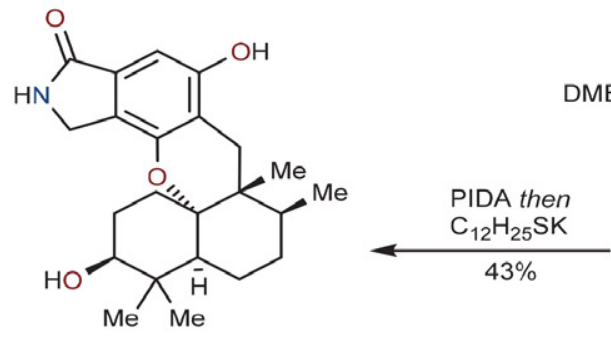

(+)-stachyflin (83)

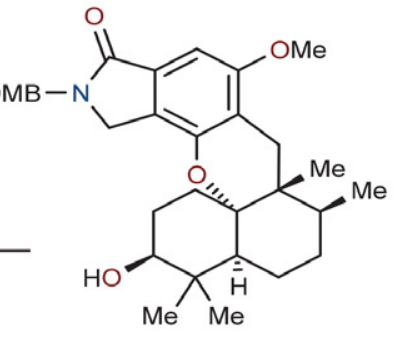

82

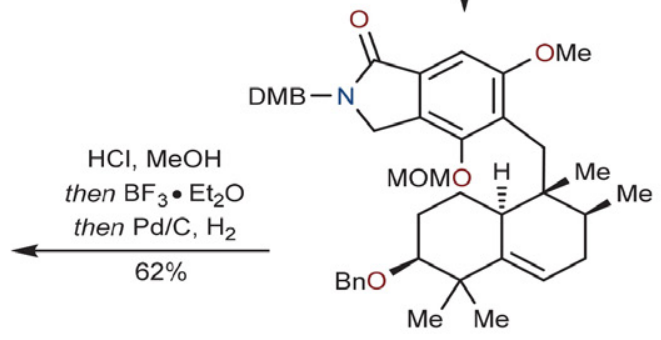

81

Scheme 9: Magauer's asymmetric total synthesis of $(+)$-stachyflin $(\mathbf{8 3}) . \mathrm{Bn}=$ benzyl. cat $=$ catechol. $\mathrm{Ms}=$ mesyl. PIDA = phenyliodine $(\mathrm{III})$ diacetate. Sphos = 2-dicyclohexylphosphino-2',6'-dimethoxybiphenyl. TBAI = tetrabutylammonium iodide. 
cursor 64. Treatment with catalytic amounts of sodium methoxide induced a retro-Claisen/esterification cascade and completed the synthesis of racemic terretonin $\mathrm{L}(\mathbf{6 5})$.

\section{7. Magauer's Total Synthesis of (+)-Stachyflin (2017)}

Six natural and 15 unnatural tetracyclic meroterpenoids were prepared in a single study by Thomas Magauer's group in late $2017 .{ }^{18}$ All these natural products were derived from simple precursors such as dimedone, cyclohexanone or cyclohexa-1,3-dione in an asymmetric, modular fashion. Their synthetic approach enabled access to a library of compounds of which thorough biological screening was performed and ultimately demonstrated the potential for improving the potency of natural products. Dime- done bis-silyl enol ether $\mathbf{6 6}$ was reacted with DMAD in an Alder-Rickert reaction. Expulsion of isobutene and concomitant silyl deprotection delivered resorcinol derivative 67 (Scheme 8). Methylation with dimethyl sulfate controllably formed 68, which was followed by $\mathrm{AlMe}_{3}$-mediated imide formation with 3,4-dimethoxybenzyl amine $\left(3,4-\mathrm{DMBNH}_{2}\right)$. Treatment of imide $\mathbf{6 9}$ with a mixture of hydroiodic and periodic acid resulted in electrophilic iodination of the phenol moiety. Finally, aryl iodide $\mathbf{7 0}$ was regioselectively reduced, and the remaining free phenol was MOM protected to yield the first coupling fragment $\mathbf{7 1}$.

The second coupling fragment was prepared in the following manner (Scheme 9). First, 2,2-dimethylcyclohexa-1,3-dione (72) underwent enantioselective CBS reduction. The secondary hydroxyl group in $\mathbf{7 3}$ was benzylated, and the ketone $\mathbf{7 4}$ was transformed into vinyl

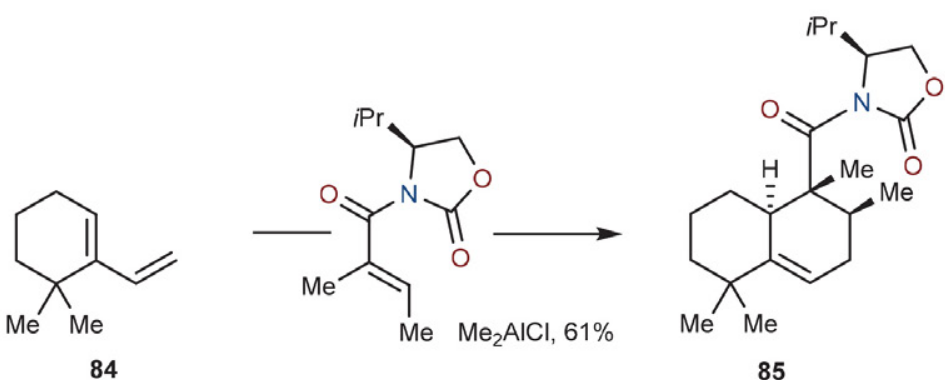

84<smiles>CC1CCC23Cc4cc(O)ccc4O[C@@]2(CCC(O)C3(C)C)C1(C)C</smiles>

$\downarrow \downarrow^{90} 5$ steps<smiles>CC1CCC2(C)C(C)(C)CCC[C@]23OC2=C(CC13C)C(=O)C(N)=CC2=O</smiles>

cyclosmenospongine (91)

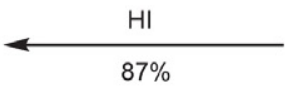<smiles>CC1CC[C@@H]2[C@]1(C)Cc1cc(O)ccc1O[C@]21CCC(O)C(C)(C)C1(C)C</smiles>

aureol (88)<smiles>COC1=CC(=O)C(O)=C(CC2(C)C(C)CC=C3C(C)(C)CCCC32O)C1=O</smiles>

mamanuthaquinone (89)

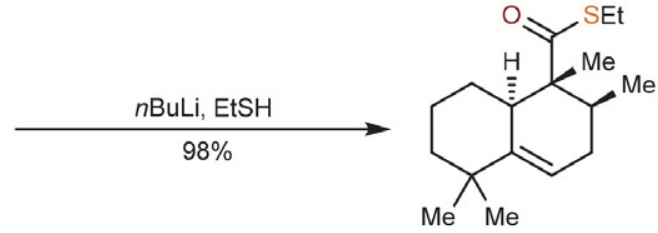

86

$\mathrm{Et}_{3} \mathrm{SiH}, \mathrm{Pd}(\mathrm{OAc})_{2}, 85 \%$<smiles>COc1ccc(OC)c(Cl)c1</smiles>

(2) $\mathrm{CS}_{2}, \mathrm{Mel}, \mathrm{NaHMDS}$ (3) AlBN, $n \mathrm{Bu}_{3} \mathrm{SnH}$

(4) $\mathrm{HCl}, \mathrm{MeOH}$ (5) $\mathrm{BF}_{3} \bullet \mathrm{Et}_{2} \mathrm{O}$ $60 \%$ over 5 steps<smiles>CC1CC=C2[C@@H](CCCC2(C)C)C1(C)C=O</smiles>

87

(1)<smiles>COc1ccc(OC)c(OC)c1Cl</smiles>

(2) $\mathrm{CS}_{2}$, Mel, NaHMDS (3) $\mathrm{AlBN}, n \mathrm{Bu}_{3} \mathrm{SnH}$

(4) $\mathrm{HCl}, \mathrm{MeOH}$

(5) salcomine, $\mathrm{O}_{2}$

$27 \%$ over 5 steps

Scheme 10: Magauer's asymmetric total syntheses of aureol (88), cyclosmenospongine (91) and mamanuthaquinone (88). AIBN = azobisisobutyronitrile. $\mathrm{HMDS}=$ hexamethyldisilazane. $\mathrm{MOM}=$ metoxymethyl. 


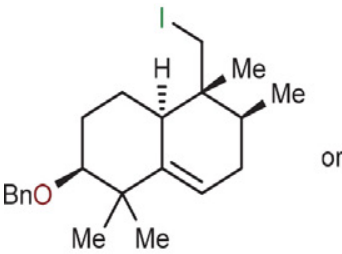

80

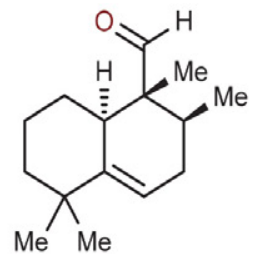

87

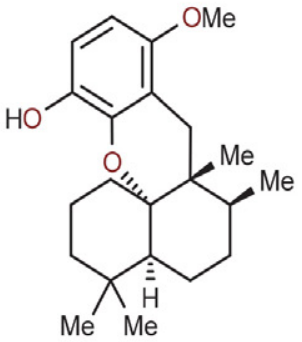

strongylin A (92)

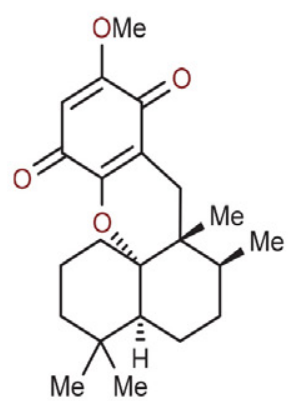

smenoqualone (93)

Scheme 11: Magauer's asymmetric total synthesis of strongylin A (92) and smenoqualone (93)

triflate 75. Stille coupling was utilized to prepare diene 76, which was later employed in a remarkable auxiliary controlled exo-selective Diels-Alder reaction to give $\mathbf{7 7}$. Evans valine-derived auxiliary was removed with in situ formed lithium ethanethiolate and the resulting thioester $\mathbf{7 8}$ was reduced with lithium aluminum hydride to the primary alcohol 79. Next, the iodide $\mathbf{8 0}$, obtained via a mesylation and substitution, underwent lithium halogen exchange. Transmetallation with $\mathrm{ZnCl}_{2}$ gave Negishi coupling partner, which in the presence of PdSPhos underwent unification with aryl iodide 71 to give 81. Deprotection of the MOM group under acidic conditions enabled $\mathrm{BF}_{3} \cdot \mathrm{Et}_{2} \mathrm{O}$-mediated cyclization, and hydrogenolysis of benzyl group gave 82. Two deprotection steps effectively revealed the free lactam and phenol motifs and completed the asymmetric total synthesis of $(+)$-stachyf$\operatorname{lin}(\mathbf{8 3})$.

Three additional natural products were analogously made from diene $\mathbf{8 4}$ in which the benzyloxy group was absent (Scheme 10). A similar Diels-Alder reaction gave cycloadduct 85 and removal of the chiral auxiliary yielded the thioester 86; this was converted into the corresponding aldehyde 87 via Fukuyama reduction. The 1,2-addition of two different aryllithiums was followed by Barton-McCombie radical deoxygenation and MOM deprotection. $\mathrm{BF}_{3} \cdot \mathrm{Et}_{2} \mathrm{O}$-mediated cyclization under kinetic control gave aureol (88) and hydroquinone oxidation gave mamanuthaquine (89), respectively. The cis-fused decalin core of aureol (88) could be isomerized into the thermodynamically more favored trans-decalin core of $\mathbf{9 0}$ using hydroiodic acid. The same group also showed that trans-decalin $\mathbf{9 0}$ could be transformed into cyclosmenospongine (91) in five steps. ${ }^{19}$

Intermediates $\mathbf{8 0}$ and $\mathbf{8 7}$ proved to be extremely versatile since $\mathrm{C}-\mathrm{C}$ bond forming reactions, either through Negishi coupling or 1,2-addition of aryllithiums, provided precursors for similar cyclization reactions. These ultimately gave rise to stronglyin A (92), smenoqualone (93) and 15 other unnatural tetracyclic meroterpenoids with either cis- or trans-decalin systems (Scheme 11).

\section{8. Poulsen's Syntheses of Stronglyophorines (2018)}

In a related pair of publications, Poulsen's group disclosed divergent syntheses of seven natural products from the strongylophorine family of meroterpenoids (Scheme 12). ${ }^{20,21}$ The carbon skeleton of this class of bioactive compounds was accessed through a unique iron(III) mediated rearrangement/cyclization cascade and $\mathrm{C}\left(\mathrm{sp}^{3}\right)-\mathrm{H} \delta$-lactonization. Development of a novel, catalytic, oxidative quinone heterofunctionalization method was necessary for the completion of the total synthesis of the STR-26 (94). Isocupressic acid (95) served as a gateway to strongylophorines; this starting material was isolated from the bark and needles of the Ponderosa pine tree.

The initial idea of direct phenol C-alkylation with an 95-derived electrophile was abandoned as it would requre laborious preparation of suitable organometallic species and thus an alternative solution was sought. Simple benzyl ester formation and Mitsunobu etherification with p-methoxyphenol set the stage for a formal [1,3]-rearrangement (96 to 97) and cyclization (97 to 98). Both transformations were efficiently promoted by the same Lewis acid $\left(\mathrm{FeCl}_{3}\right)$. Ortho-selective phenol C-alkylation was therefore achieved through the intermediacy of O-alkylated product 96 . Debenzylation of 98 with palladium on carbon gave STR-1 (99) and further demethylation with pyridinium chloride at elevated temperatures gave STR-3 (100). Alternatively, amide formation with HATU in the presence of 1-hydroxy-7-azabenzotriazole (HOAt) furnished 101, which was then exposed to in situ formed AcOI, generated from lead tetraacetate (LTA) and elemental iodine under UV light. This protocol was able to selectively oxidize the $\gamma$-methyl substituent in the presence of an electron-rich arene, even with competing benzylic oxidation. Lactonization via amide hydrolysis and dehydroiodination of 102 yielded unsaturated intermediate 103. The styrene moiety was diastereoselectively hydrogenated with palladium on carbon and in situ formed TMSI successfully demethylated STR-9 (104) to give STR2 (105). STR-8 (106) was prepared from STR-2 (105) by oxidative opening of the chromane system with $\mathrm{NaIO}_{4}$ and 

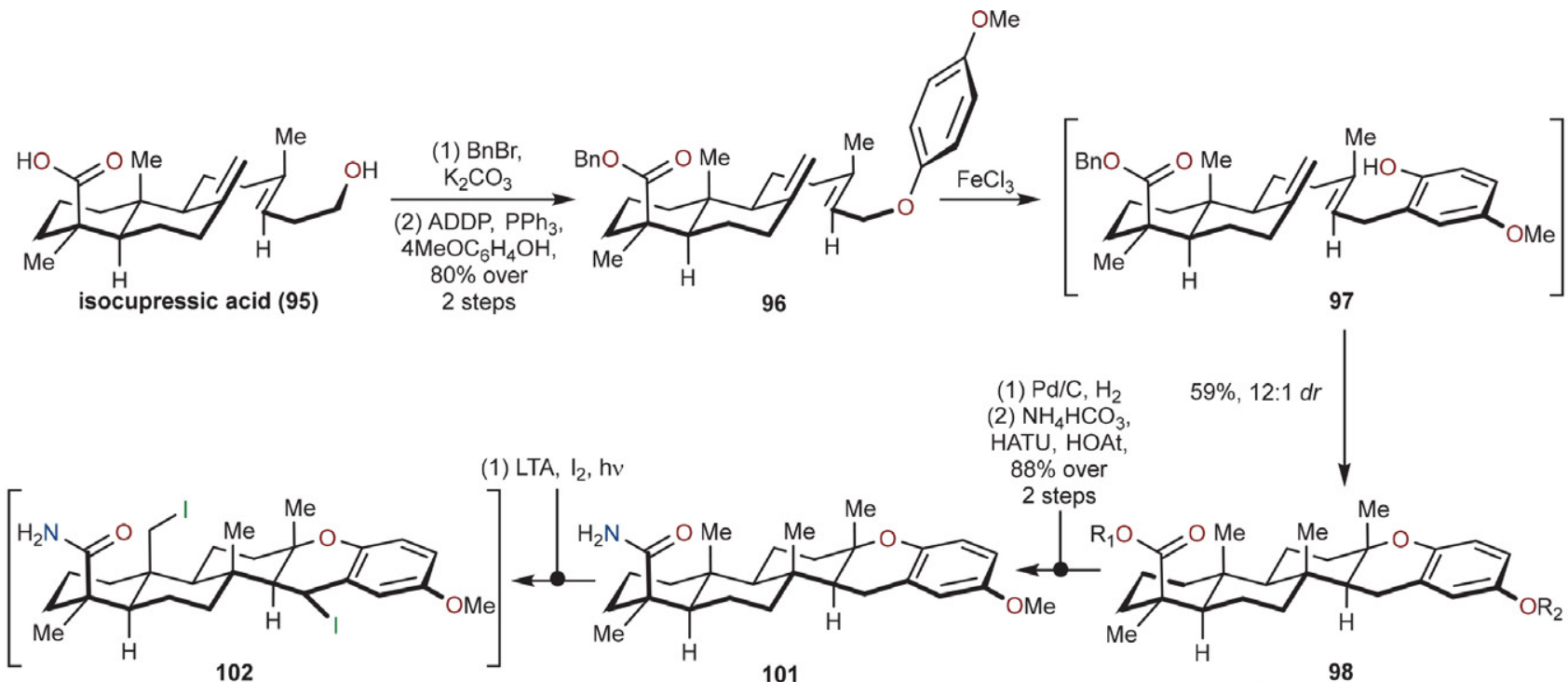

(1) LTA, I , hv

(2) $\mathrm{KOH}, \mathrm{MeOH}$

(3) $\mathrm{HCl}, 58 \%$ over 3 steps

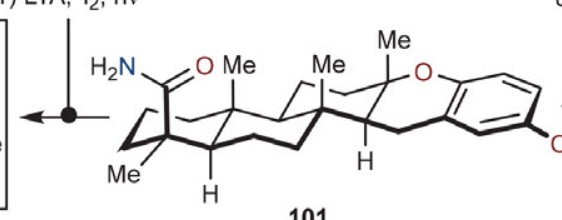

101
(1) $\mathrm{Pd} / \mathrm{C}, \mathrm{H}_{2}$
(2) $\mathrm{NH}_{4} \mathrm{HCO}_{3}, \quad 59 \%, 12: 1 d r$
HATU, HOAt,
$88 \%$ over

2 steps

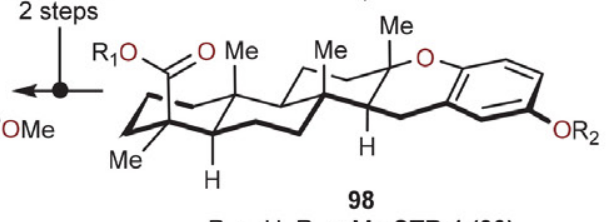

$R_{1}=H, R_{2}=$ Me STR -1 (99)

$R_{1}=R_{2}=H$ STR -3 (100)

$\checkmark$

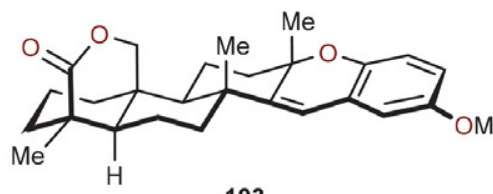

103
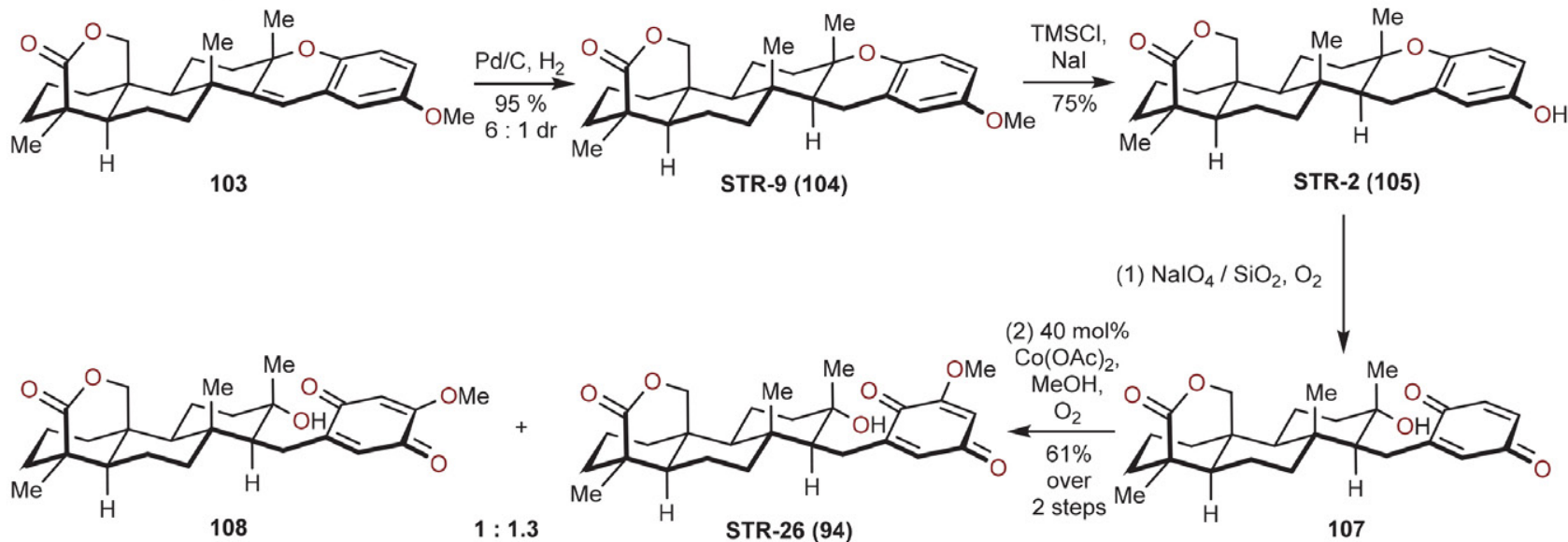

$1: 1.3$

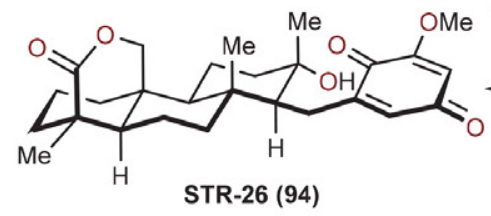

(2) $40 \mathrm{~mol} \%$

(1) $\mathrm{NaIO}_{4} / \mathrm{SiO}_{2}, \mathrm{O}_{2}$

$\mathrm{Co}(\mathrm{OAc})_{2}$
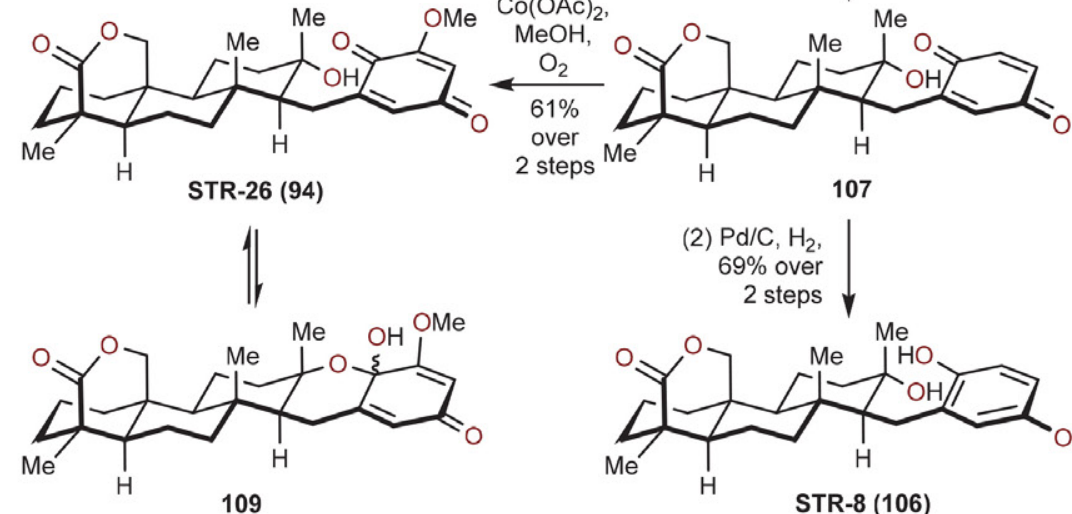

(2) $\mathrm{Pd} / \mathrm{C}, \mathrm{H}_{2}$, $69 \%$ over 2 steps

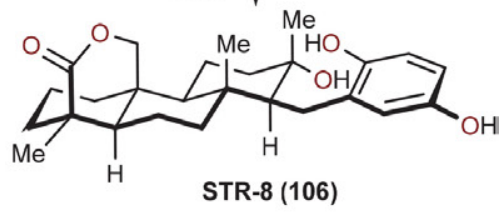

Scheme 12: Poulsen's semisyntheses of stronglyphorines. ADDP = 1,1'-(azodicarbonyl)dipiperidine. $\mathrm{Bn}=$ benzyl. HATU = 1-[bis (dimethylamino) methylene]-1H-1,2,3-triazolo[4,5-b]pyridinium 3-oxide hexafluorophosphate. HOAt $=1$-hydroxy-7-azabenzotriazole. LTA $=$ lead tetraacetate. TMS = trimethylsilyl

molecular oxygen with further hydrogenation of the 1,4-benzoquinone motif. Transiently formed 1,4-benzoquinone 107 could be exposed to oxidative heterofunctionalization conditions using $\mathrm{Co}(\mathrm{OAc})_{2}$ to give SRT-26 (94) alongside its constitutional isomer 108 in a 1.3:1 ratio.
The former is in equilibrium with two diastereomeric hemiketals 109. Catalytic oxidative heterofunctionalization methodology deserves a special mention as it enables controlled functionalization of 1,4-benzoquinone and its derivatives with oxygen, nitrogen and sulfur nucleophiles. 


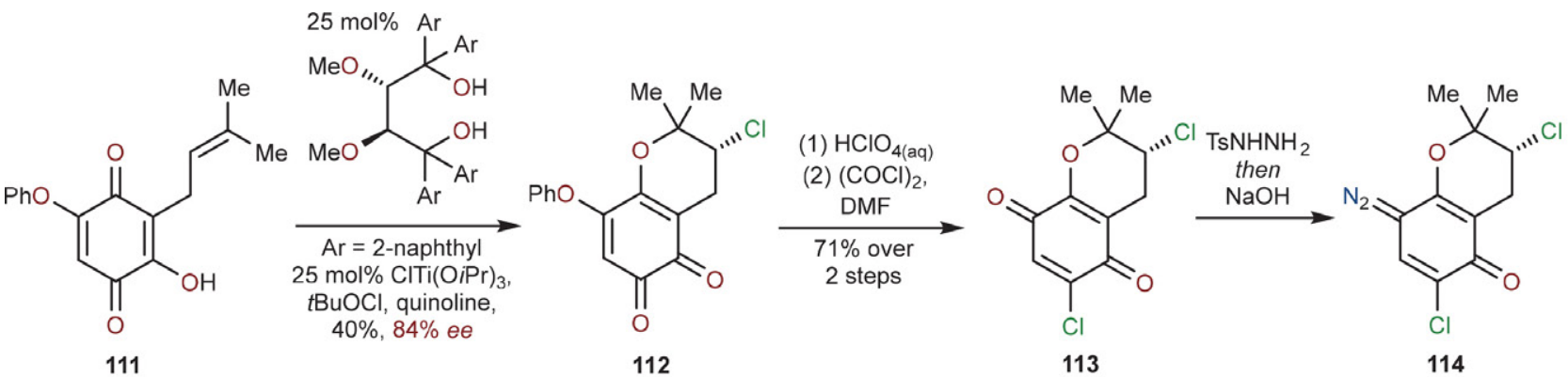

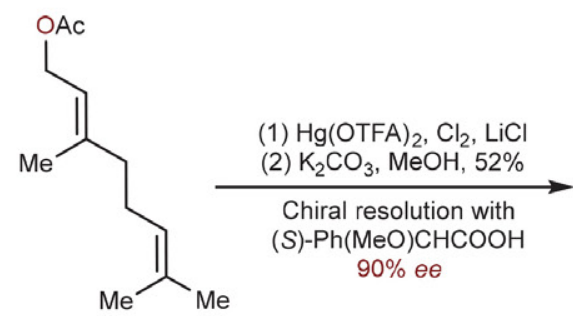

116

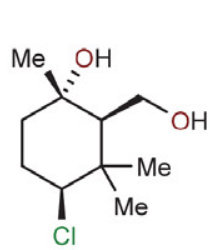

117
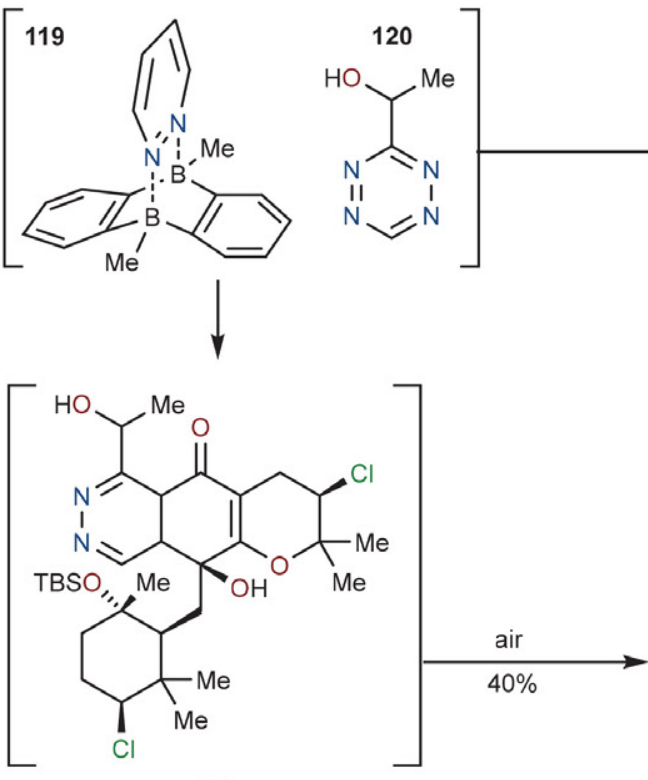

122

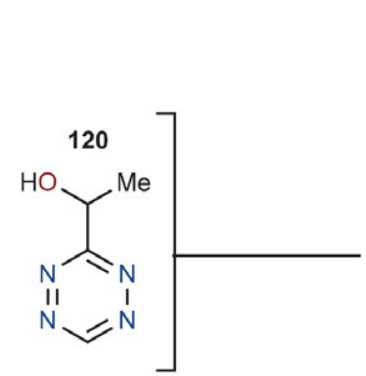<smiles>CC(C)(C)O[C@]1(C)CC[C@@H](Cl)C(C)(C)[C@@H]1CC1(O)C=CC(=O)C2=C1OC(C)(C)C(Cl)C2</smiles>

121

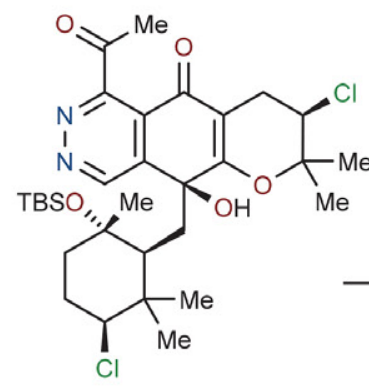

123

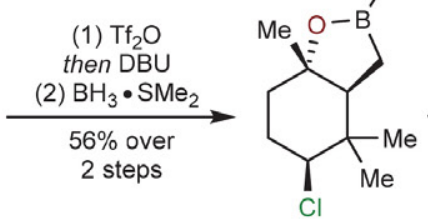

115

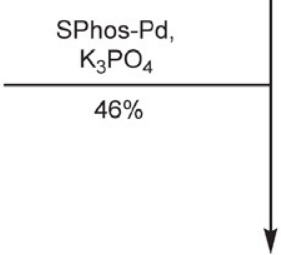

(1) SPhos-Pd, $\mathrm{K}_{2} \mathrm{CO}_{3}$

(2) TBSOTf (3) PIFA

\section{$20 \%$ over} 3 steps<smiles>CC1(C)Oc2c(CC3C(C)(C)C(Cl)CC[C@@]3(C)O)cc(Cl)c(O)c2CC1Cl</smiles>

118<smiles>CC(=O)c1nncc2c1C(=O)C1=C(OC(C)(C)[C@H](Cl)C1)[C@@]2(O)C[C@H]1C(C)(C)[C@@H](Cl)CC[C@]1(C)O</smiles>

azamerone (110)

Scheme 13: Burns' asymmetric total synthesis of azamerone (110). DBU = 1,8-diazabicyclo[5.4.0] undec-7-ene. DMF $=N, N$-dimethylformamide. PIFA = phenyliodine(III) bis(trifluoroacetate). Sphos = 2-dicyclohexylphosphino-2',6'-dimethoxybiphenyl. TBS = tert-butyldimethylsilyl. Tf $=$ triflyl. TFA = trifluoroacetate.

\section{9. Burns' Total Synthesis of Azamerone (2019)}

Azamerone (110) presents as a fascinating chlorinated natural product containing a phthalazinone core from the napyradiomycin subset of meroterpenoids. Its biogenesis can be traced back to an $\alpha$-diazoketone motif-containing intermediate (not shown) (Scheme 13). ${ }^{22}$ The first enantioselective chemical synthesis of azamerone (110) was published in early 2019 by Burns' group, whose work contributes to the development of enantioselective chloroetherification methods of nonstabilized olefins. Key features of the synthetic route include a two-step mimic of halopolyene cyclizations and Suzuki coupling with a quinone diazide.

Azamerone (110) was traced back to prenylated hydroxyquinone 111, which was prepared in four steps from 


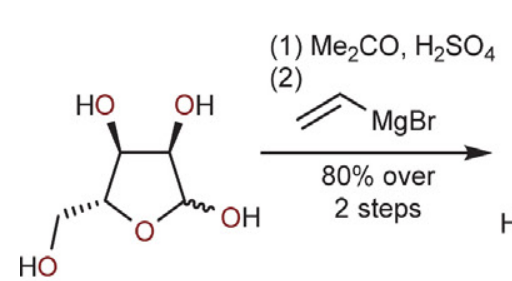

127

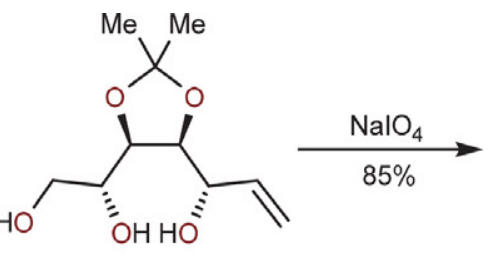

128<smiles>C=C[C@@H]1O[C@H](O)[C@H]2OC(C)(C)O[C@H]12</smiles>

129<smiles>C=C[C@H](O)C1OC(C)(C)O[C@@H]1C=C</smiles>

130

(1) $3 \mathrm{~mol} \%$

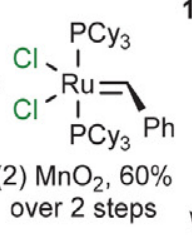<smiles>CCC(C)=CCCC(C)=CCC(C)(C)C</smiles>

$\alpha$-humulene (12)

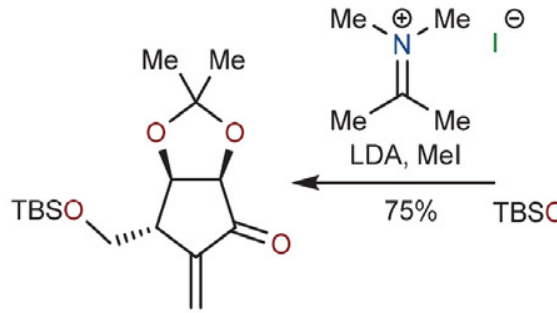

133<smiles>CC1(C)O[C@H]2C(=O)C[C@H](CO)[C@H]2O1</smiles>

132<smiles>CC1(C)O[C@H]2C=CC(=O)[C@H]2O1</smiles>

131

(1) $\triangle$

(2) TBAF, $51 \%$ over 2 steps

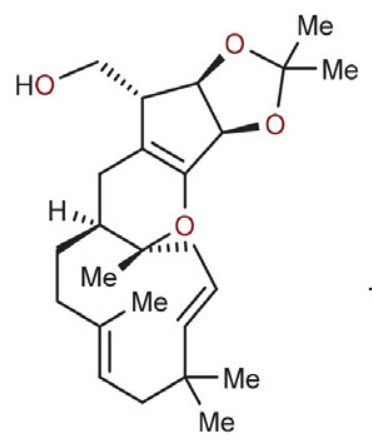

134

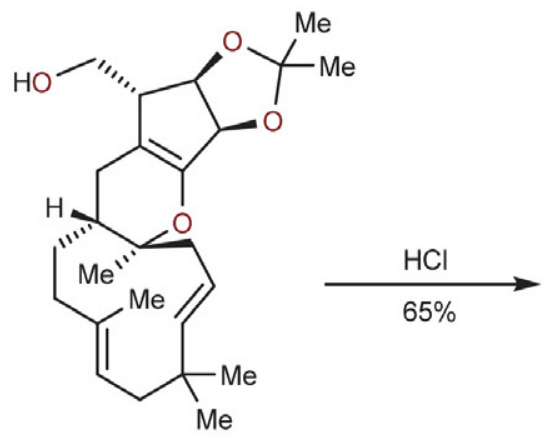

$2: 1$

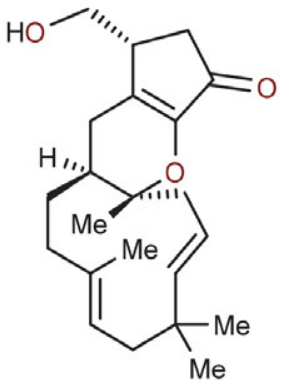

136

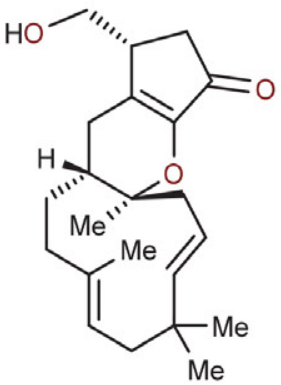

137

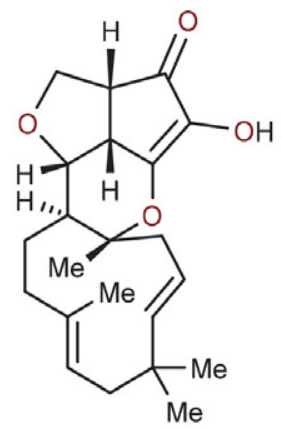

xenovulene A (124)

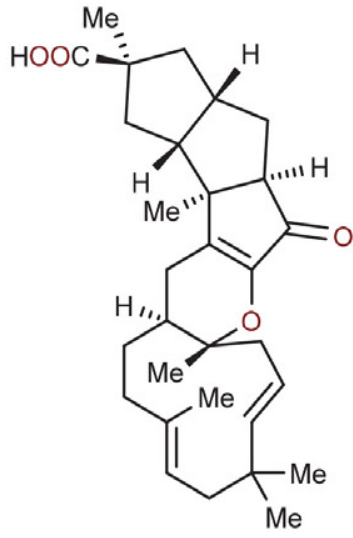

sterhirsutin A (125)
(1) $20 \mathrm{~mol} \% \mathrm{Ph}_{2} \mathrm{CO}$, $\frac{\mathrm{h} v, \mathrm{MeOH}}{(2) \mathrm{TBSCl}}$ DMAP, imidazole, $65 \%$ over 2 steps 
catechol. Developed for this purpose, titanium mediated enantioselective intramolecular chloroetherification of $\mathbf{1 1 1}$ gave benzochloropyran 112, which was later hydrolyzed with aqueous perchloric acid and chlorinated with a mixture of oxalyl chloride and DMF. The decomposition of the corresponding tosyl hydrazone from $\mathbf{1 1 3}$ gave diazo compound 114, which was used directly without purification in the subsequent Suzuki coupling reaction. The other coupling partner, boronic hemiester 115, was prepared from geranyl acetate (116). Mercury trifluroacetate-mediated polyene cyclization, acetate deprotection and chiral resolution via ester formation with (S)- $\alpha$-methoxyphenylacetic acid gave enantioenriched intermediate 117. Triflation, DBU-promoted elimination and hydroboration were needed to complete the synthesis of $\mathbf{1 1 5}$. Suzuki coupling (yielding 118) was followed by palladium-catalyzed dechlorination, silyl protection of the tertiary alcohol and PIFA oxida- tion. Bis-boron complex 119 was then employed to catalyze the inverse electron demand Diels-Alder reaction between tetrazine $\mathbf{1 2 0}$ and 121. Following [4+2]-retrocycloadition and nitrogen expulsion, dihydropyridazine 122 underwent spontaneous aromatization and benzylic alcohol oxidation to give silyl protected azamerone 123. Acidic deprotection of the remaining silyl protecting group with aqueous hydrochloric acid furnished the desired natural product $\mathbf{1 1 0}$.

\section{10. Kirschning's Studies Towards 5,6,11-Tricyclic Meroterpenoids (2019)}

Meroterpenoids xenovulene A (124), sterhirsutin A (125), and sterhirsutin B (126) share a similar 5,6,11-tricyclic core despite being isolated from different fungi (Scheme 14). Work done by Kirschning's group marks another milestone in the exploration of hetero-Diels-Alder<smiles>CC(=O)c1c(O)cc(O)cc1CCC(Cl)(Cl)Cl</smiles>

8<smiles>CC(=O)C1=C(O)C(C)(C)C(=O)C(C)(C)C1=O</smiles>

139

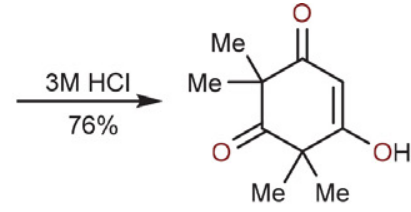

syncarpic acid (140)

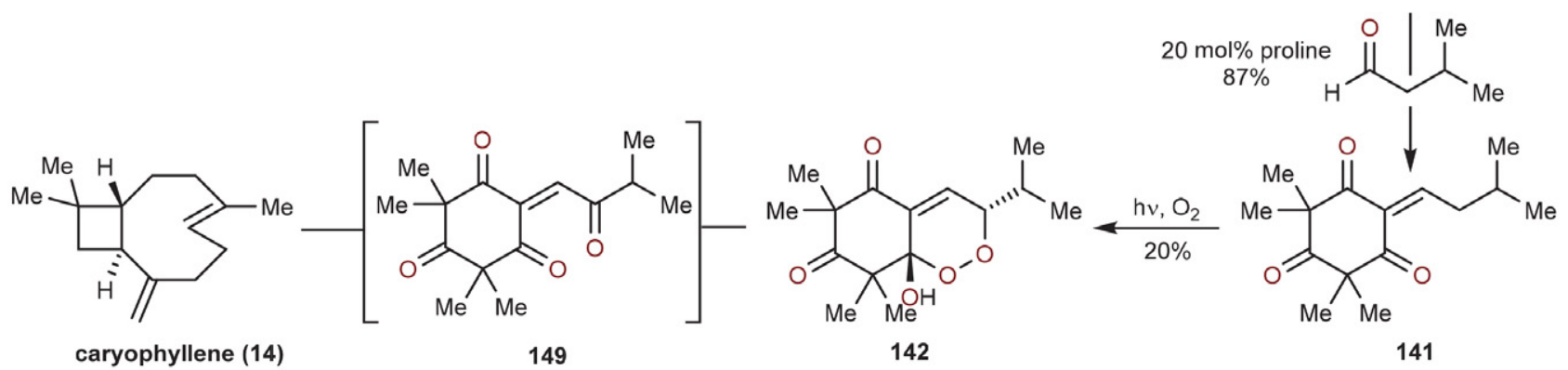

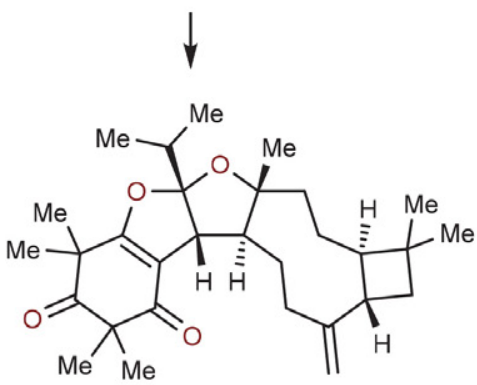

rhodomyrtusial A $(147,4 \%)$

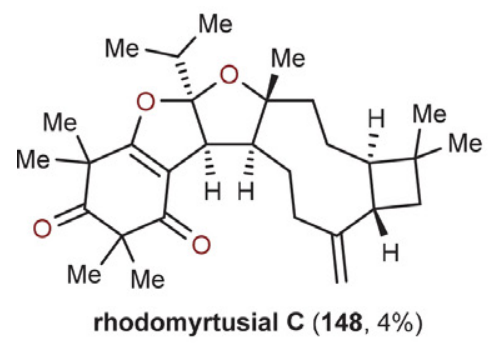

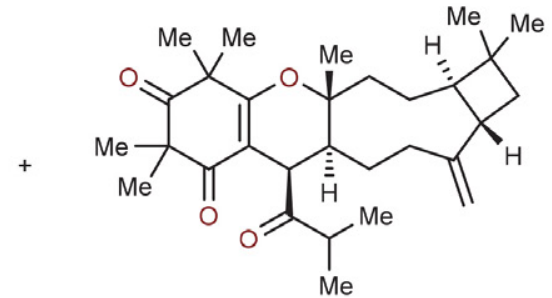

rhotomentodione A (146, 19\%)

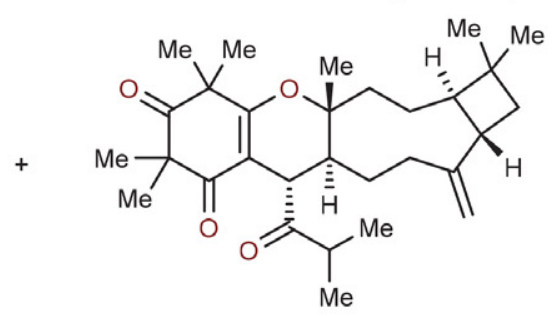

tomentodione $\mathrm{R}(\mathbf{1 4 5}, 15 \%)$<smiles>C=C(CC[C@@]12C(C(=O)C(C)C)C3=C(O[C@](C)(CC[C@@H]4[C@H](C)CC4(C)C)C1C3=O)C(C)(C)C(=O)C2(C)C)C(C)C</smiles>

rhotomentodione B $(143,5 \%)$

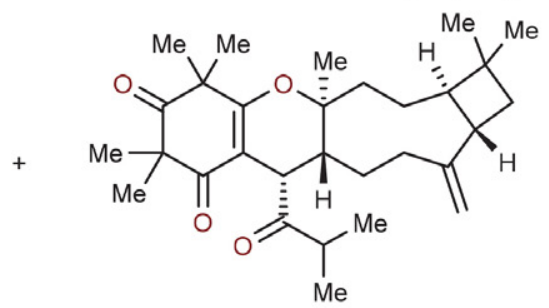

tomentodione $Q(144,8 \%)$

Scheme 15: Liu's and Porco's biomimetic total syntheses of meroterpenoids from Rhodomyrtus tomentosa. Ac $=$ acetyl. 
chemistry between ortho-quinone methides and $\alpha$-humulene (12). ${ }^{23}$ Using this approach, they were able to access the aforementioned core starting from commercially available chiral pool material D-ribose (127). The protected acetonide form was treated with vinyl magnesium bromide to yield 128 , which subjection with $\mathrm{NaIO}_{4}$ oxidatively cleaved the diol to the resulting aldehyde which spontaneously formed lactol 129. Standard Wittig olefination installed the second vinyl handle in 130, which was needed for ring-closing metathesis. Introduction of the first-generation Grubbs catalyst effectively forged a five-membered ring containing an allylic alcohol moiety (not shown) via RCM, which was successively oxidized with $\mathrm{MnO}_{2}$ to provide enone 131. Photochemical 1,4-addition of methanol and silyl protection yielded ketone $\mathbf{1 3 2}$. The reactive exocyclic methylene group in $\mathbf{1 3 3}$ was appended using Es- chenmoser methenylation. The key chemoselective hetero-Diels-Alder reaction with $\alpha$-humulene (12) gave a 2:1 mixture of products 134 and $\mathbf{1 3 5}$ after silyl deprotection. Enones 136 and 137 were formed via acid catalyzed rearrangements of the corresponding acetonides. The authors speculate that this transformation occurs through transient double bond isomerization and expulsion of acetone.

\section{11. Liu's and Porco's Total Syntheses of Rhodomyrtus Tomentosa Meroterpenoids (2019)}

Collaboratorative efforts from Liu and Porco groups resulted in isolation of seven meroterpenoids from the leaves and stems of Rhodomyrtus tomentosa, evaluation of their AchE inhibitory activities, as well as their prepara-<smiles>COC/C=C(\C)CC/C=C(\CC1OC1(C)C)CC1OC1(C)CC1OC1(C)C</smiles3,5-dimethylorsellinic acid (150)

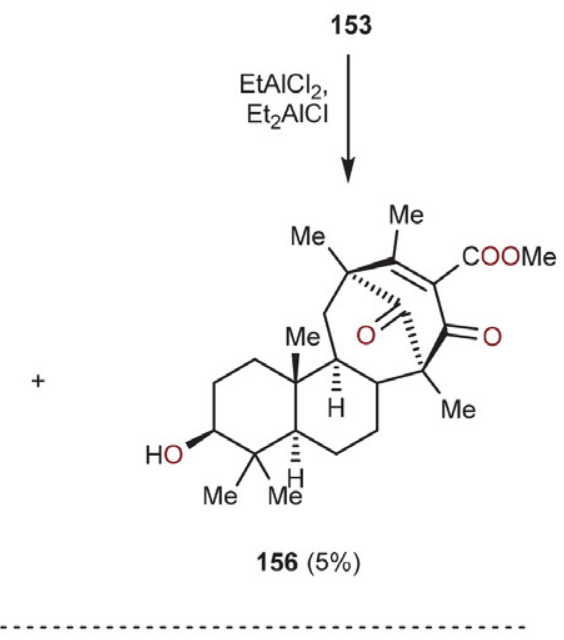<smiles>CC(=O)CCC=C(C)CC1OC1(C)C</smiles><smiles>CC(=O)C1=C(C)C(C)(C/C=C(\C)CC/C=C(\C)CC2OC2(C)C)C(O)=C(C(C)=O)C1=O</smiles>

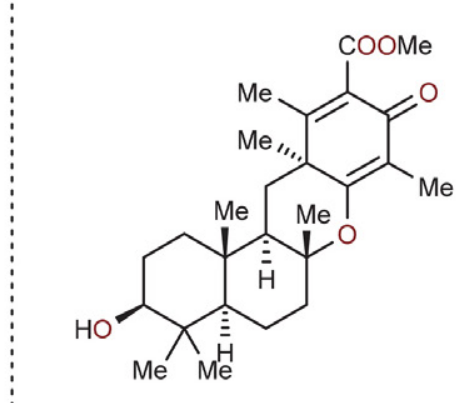

$155(16 \%)$

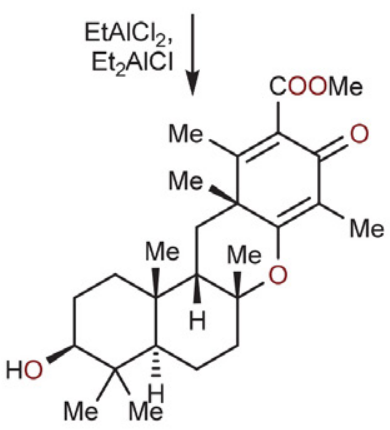

$157(11 \%)$

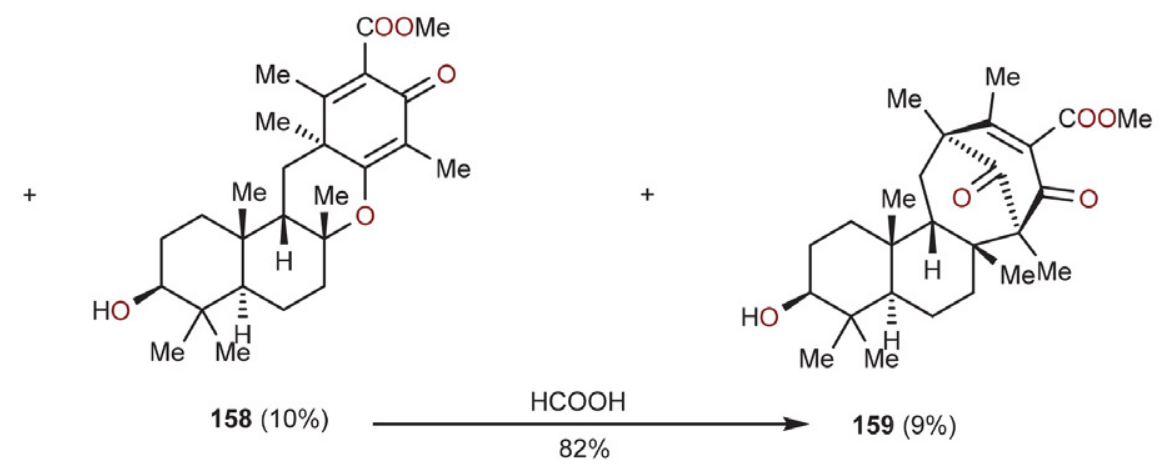

Scheme 16: Porco's biomimetic synthesis of meroterpenoids 155, 156, 157 and 158. HMDS = hexamethyldisilazane. TMS = trimethylsilyl . 
tion in six steps from commercially available starting materials. Their synthesis began with Friedel-Crafts acylation of phloroglucinol 8 (Scheme 15). Orcinol derivative 138 was dearomatized by exhaustive methylation with MeI / $\mathrm{NaOMe}$. Acid catalyzed deacylation of 139 provided syncarpic acid 140, which was then used in a proline catalyzed intermolecular aldol condensation with isovaleraldehyde. Afterwards, singlet oxygen [4+2]-cycloaddition with $\mathbf{1 4 1}$ gave a separable mixture of syn- (not shown) and anti-hy- droxy-endoperoxide (142) in 52\% and 20\% yields respectively. It was found that anti-hydroxy-endoperoxide could be thermally equilibrated into a 1.5:1 mixture of syn-and anti-hydroxy-endoperoxides. Reactivity of both diastereoisomers with caryophyllene (14) was tested in the presence of molecular sieves. While the syn-diastereoisomer gave only a mixture of rhotomentodione B (143) and tomentodiones Q (144) and R (145) in the thermolysis reaction, the anti-diastereoisomer also provided rhotomento-<smiles>CC1(C)CCC[C@]2(C)[C@H]1CC[C@@]1(C)OC(=O)C[C@]12C</smiles>

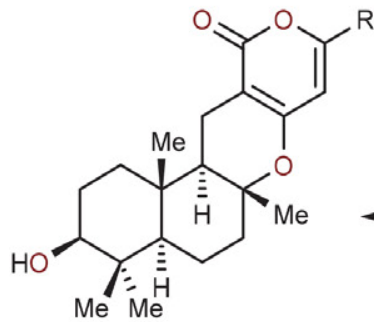

arisugacin $\mathrm{F}(\mathbf{1 6 0})$ $\mathrm{R}=4-\mathrm{MeOC}_{6} \mathrm{H}_{4}$ $53 \%$ over 2 steps<smiles>CC(=O)O[C@H]1CC[C@]2(C)[C@H](C)[C@]3(C)CC[C@]4(C)Oc5cc(F)oc(=O)c5C[C@]4(C)[C@]3(C)[C@]12C</smiles>

phenylpyropene C (164) $\mathrm{R}=\mathrm{Ph}$

$58 \%$ over 3 steps

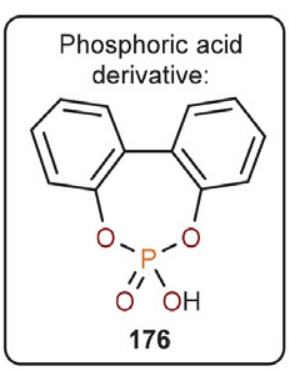

(1) $55 \%, 10: 1 d r$

(2) $87 \%, 12: 1 d r$<smiles>[R]c1cc(O)cc(=O)o1</smiles>

cat. phos. acid

176 then

$\mathrm{Mn}(\mathrm{dpm})_{3}$,

TBHP, $\mathrm{PhSiH}_{3}$

1) $64 \%, 10: 1 d r$

(2) $90 \%, 20: 1 d r$<smiles>CC1(C)[C@@H](O)CC[C@]2(C)[C@@H](C=O)[C@@](C)(O)CC[C@@]12C</smiles>

173

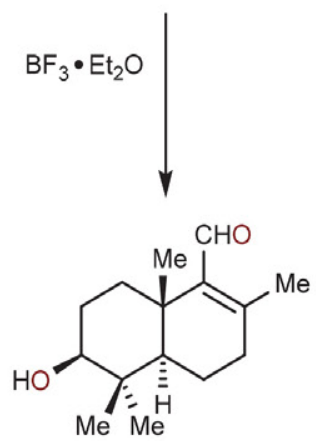

174
(1) $\mathrm{NaOCl}, \mathrm{NaHPO}_{4}$, 2-methyl-2-butene (2) $\mathrm{Ac}_{2} \mathrm{O}, \mathrm{DMAP}, \mathrm{py}$, $63 \%$ over 2 steps (3) cat. DMF, $(\mathrm{COCl})_{2}$<smiles>CC(=O)C1=C(C)CC[C@]2(C)C1(C)CC[C@@H](OC(C)(F)F)C2(C)C</smiles>

(1) TMSCl, imidazole, DMAP

(2) KHMDS, $\mathrm{O}_{2}$ $\mathrm{P}(\mathrm{OMe})_{3}$

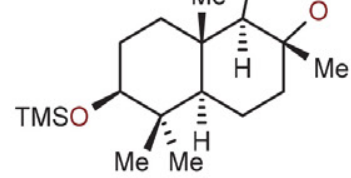
171

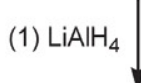

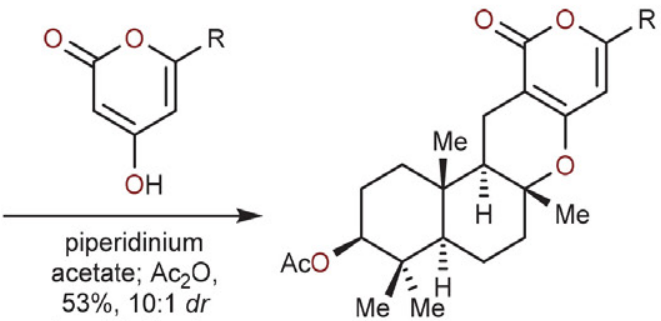

then $\mathrm{Mn}(\mathrm{dpm})_{3}$, TBHP, $\mathrm{PhSiH}_{3}$, $40 \%, 8: 1 d r$

pyripyropene $E$ (161) $R=3-p y$

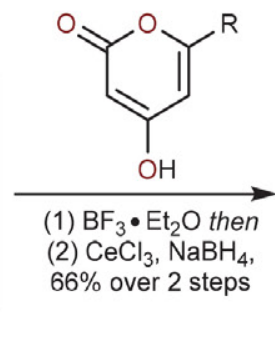

Scheme 17: Renata’s chemoenzymatic total synthesis of arisugacin $\mathrm{F}(\mathbf{1 6 0})$, pyripyropene $\mathrm{E}(\mathbf{1 6 1})$ and phenylpyropenes $\mathrm{C}(\mathbf{1 6 4})$ and $\mathrm{F}(\mathbf{1 6 5})$. Ac $=$ acetyl. DMAP = 4-dimethylaminopyridine. $\mathrm{HMDS}=$ hexamethyldisilazane. $\mathrm{TBHP}=$ tert-butyl hydroperoxide. $\mathrm{TMS}=$ trimethylsilyl. 


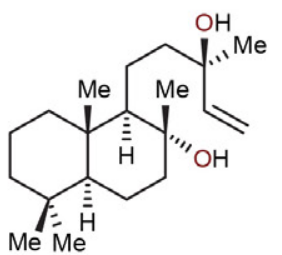

sclareol (169)
(1) Acryloyl chloride

DMAP, $\mathrm{PhNMe}_{2}$

(2) $5 \mathrm{~mol} \%$ Grubbs II

(3) $\mathrm{NaHCO}_{3}$, DMSO

$78 \%$ over 3 steps<smiles>CCC1C(C)=CC[C@@H](C)[C@@]1(C)CC[C@]1(C)CC[C@@H](O)[C@H](C)C1(C)C</smiles>

181

(1)

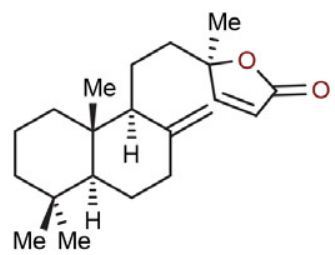

177

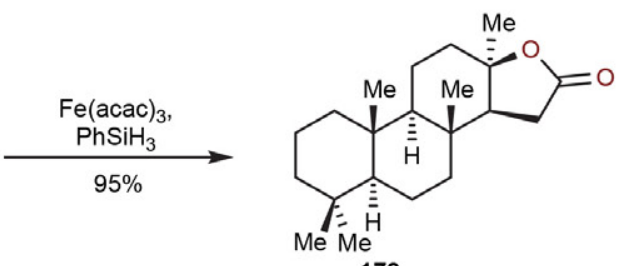

178

Lil, 2,6-lutidine, $77 \%$ over 2 steps

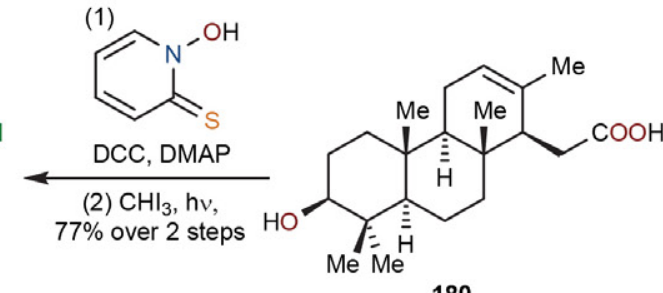

P450

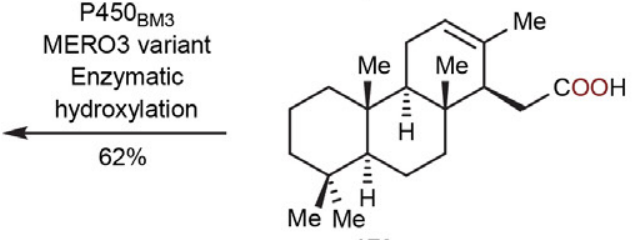

179

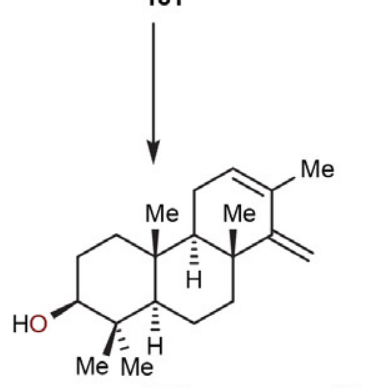

185

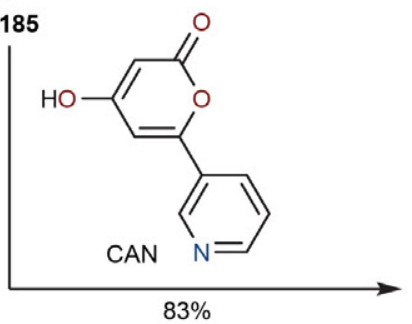

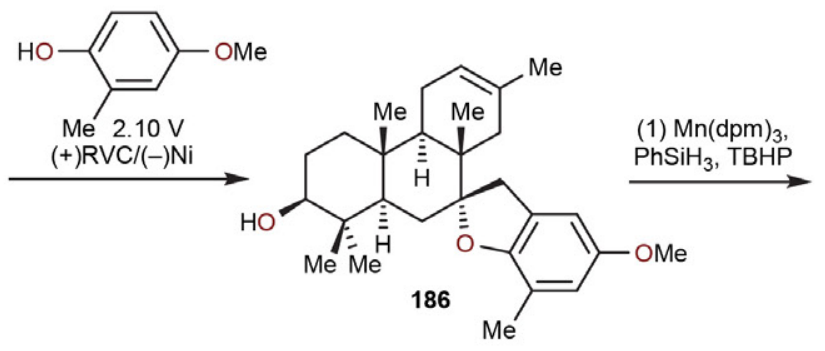

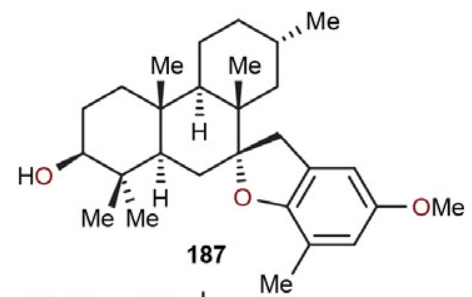

(2) $\mathrm{BBr}_{3}, 68 \%$ over 2 steps

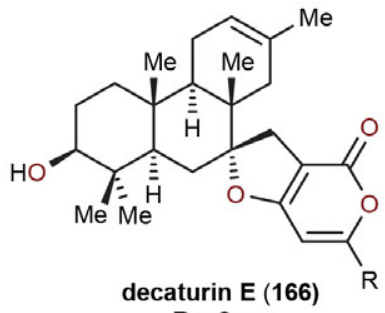
$\mathbf{R}=\mathbf{3}$-py

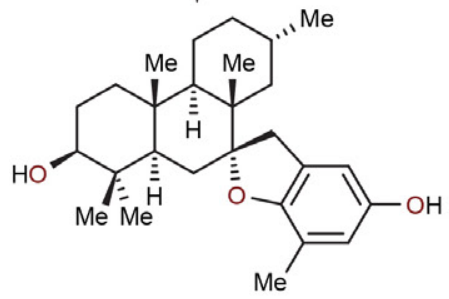

stypodiol (163)

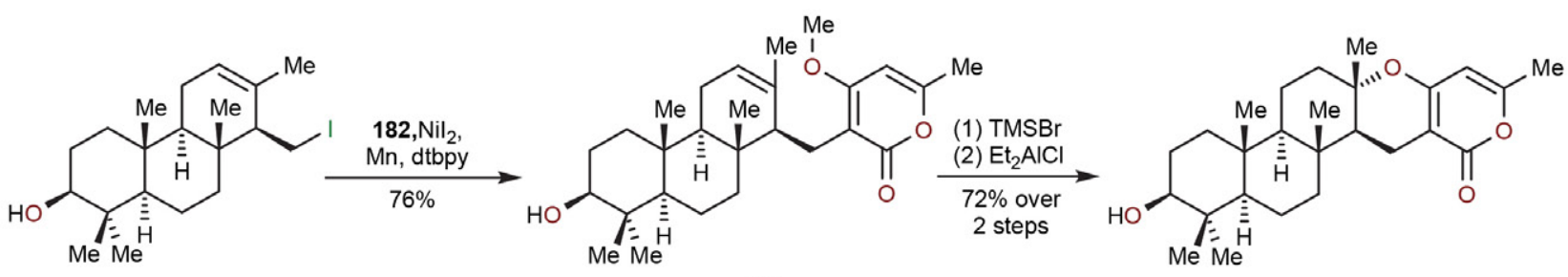

181

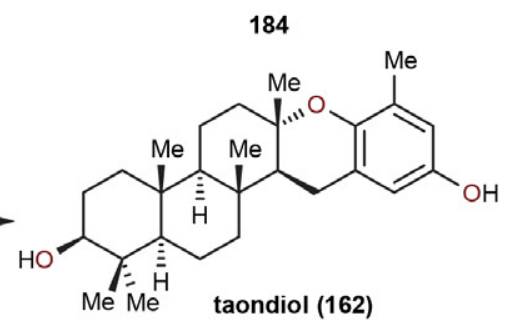

chevalone A (167)

1) $183, \mathrm{Nil}_{2}, \mathrm{Mn}$, dtbpy

(2) $\mathrm{CAN}, \mathrm{Na}_{2} \mathrm{~S}_{2} \mathrm{O}_{4}$

(3) $\mathrm{TsOH}, 53 \%$ over 3 steps

taondiol (162)

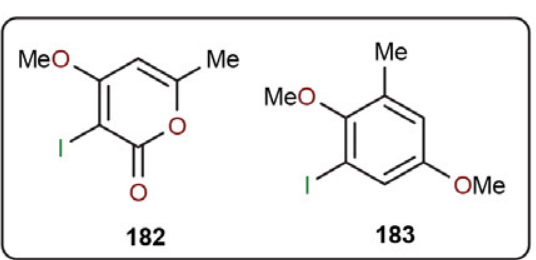

Scheme 18: Renata’s chemoenzymatic total synthesis of decaturin E (166), stypodiol (163), chevalone A (167) and taondiol (162). acac = acetylacetonate. $\mathrm{CAN}=$ cerium(IV) ammonium nitrate. $\mathrm{DMAP}=4$-dimethylaminopyridine. $\mathrm{DMSO}=$ dimethyl sulfoxide. $\mathrm{RVC}=$ reticulated vitreous carbon. $\mathrm{dtbpy}=4,4^{\prime}$-di-tert-butyl-2,2'-dipyridine. TBHP = tert-butyl hydroperoxide. TMS $=$ trimethylsilyl. Ts $=$ tosyl. 
dione A (146) as well as both rhodomyrtusials A (147) and $\mathrm{C}$ (148). The authors propose that both hydroxy-endoperoxides form the same reactive enetrione species (149) in situ, albeit, different mechanisms of formation could be operational. The chemistry of enetrione (149) was further explored as it displayed interesting modes of reactivity. Initial computational study indicated that asynchronous concerted hetero-Diels-Alder might be operational instead of the initially proposed stepwise Michael addition pathway. The latter mode resembles reactivity observed by the Cramer's group during their synthesis of psiguadial B (16) (Scheme 4).

\section{12. Porco's Total Syntheses of DMOA- derived Meroterpenoids (2019)}

As an addition to Maimone's and Newhouse's work on polyene cyclization derived meroterpenoids, the group of Porco devised their own syntheses of meroterpenoids using a biomimetic approach. ${ }^{24}$ Their strategy features polyene cyclization with a dearomatized moiety acting as a terminating group. Development of selective alkylation procedure for 3,5-dimethylorsellinic acid (DMOA, 150) was crucial for the preparation of suitable precursors for the aforementioned cyclization step (Scheme 16). The trianion of $\mathbf{1 5 0}$, formed in the presence of excess LiHMDS, was selectively alkylated with different electrophiles (such as $\mathbf{1 5 1}$ and 152) at the $\mathrm{C} 5$ position (instead of the C3 position). Methylation employing trimethylsilyl diazomethane gave rise to precursors 153 and 154, which would, upon treatment with $\mathrm{Et}_{2} \mathrm{AlCl}$ and Et $\mathrm{AlCl}_{2}$, furnish a mixture of tri- and tetracyclic meroterpenoids $(155,156,157,158$ and 159). They also demonstrated that formic acid would transform kinetic O-alkylated cyclization product $\mathbf{1 5 8}$ into thermodynamically more favored C-alkylated product $\mathbf{1 5 9}$ as suggested by relative energy levels of cyclized meroterpenoids based on computational studies.

\section{13. Renata's Total Syntheses of $\alpha$-Pyrone and Diterpene Meroterpenoids (2020)}

In early 2020, Renata's group accessed eight natural products from $\alpha$-pyrone and diterpene meroterpenoids subsets in a concise, high-yielding and modular fashion. ${ }^{25}$ While some of them [arisugacin $\mathrm{F}(\mathbf{1 6 0})^{26}$, pyripyropene $\mathrm{E}(\mathbf{1 6 1})^{27}$, taondiol $(\mathbf{1 6 2})^{28,29}$, and stypodiol $(\mathbf{1 6 3})^{30}$ ] have been subjects of multiple synthetic studies, others [phenylpyropenes $\mathrm{C}$ (164) and F (165), decaturin E (166) and chevalone A (167)] were synthesized for the first time. Instead of using more conventional WielandMischer ketone, sclareolide (168) and sclareol (169) were

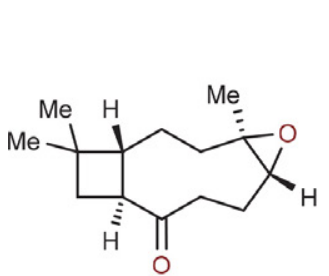

(-)-kobusone (190)

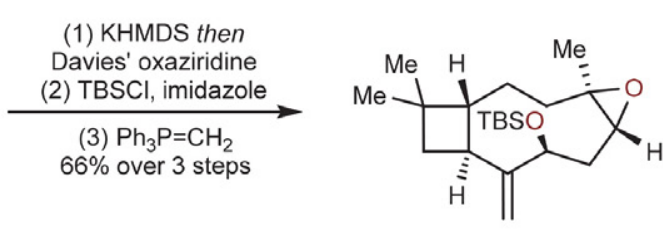

191

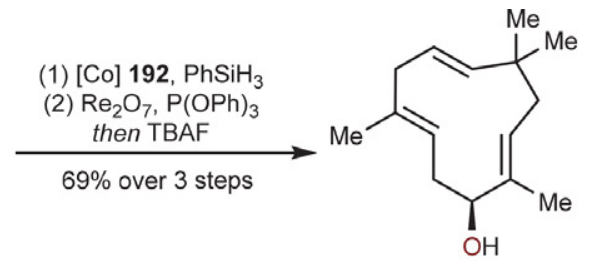

10-hydroxyhumulene (193)

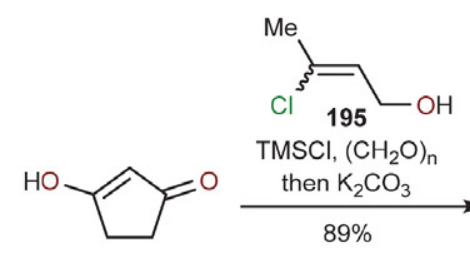

194

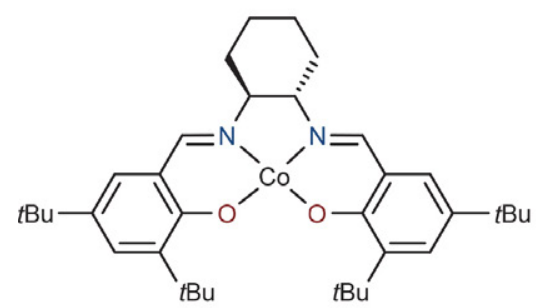

[Co] 192

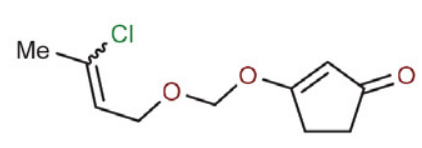

196

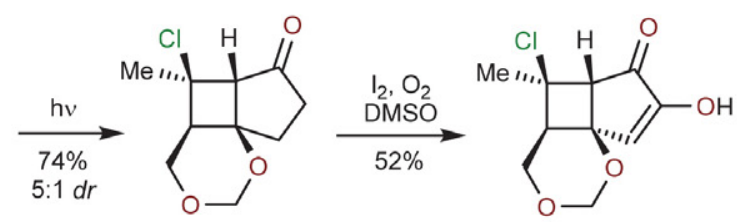

197

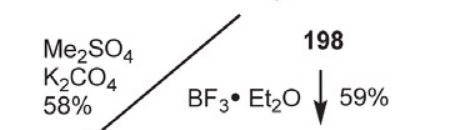

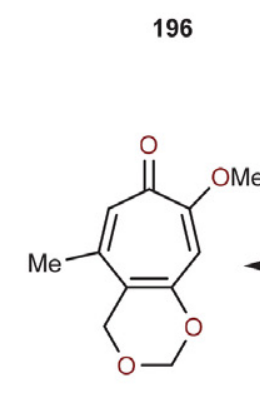

201

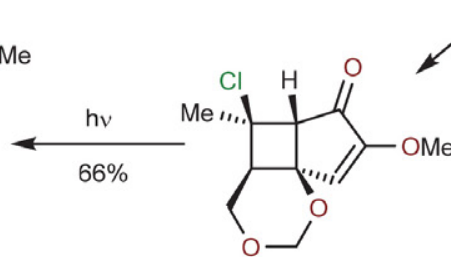

200

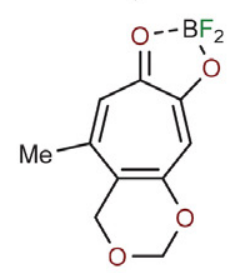

199

Scheme 19: Sarlah's syntheses of 10-hydroxyhumulene and two tropolone-derived ortho-quinone methide precursors. DMSO = dimethyl sulfoxide. TBAF $=$ tetrabutylammonium fluoride. TBS $=$ tert-butyldimethylsilyl. TMS $=$ trimethylsilyl. 
selected as commercially available, chiral pool starting materials. Traditional polar disconnections were replaced by a combination of radical chemistry and biocatalysis. 168 was successfully utilized for chemo-, regioand diastereoselective $\mathrm{C}-\mathrm{H}$ oxidation to install a hydrox$\mathrm{yl}$ group at the $\mathrm{C} 3$ position of the sclareolide drimane scaffold (Scheme 17). Silyl protection of the newly formed hydroxy group in $\mathbf{1 7 0}$ with trimethylsilyl chloride was followed by diastereoselective -oxygenation. Reduction of the lactone $\mathbf{1 7 1}$ with lithium aluminum hydride gave a mixture of a lactol and a triol 172 (unified structure shown). Convergent oxidative cleavage with $\mathrm{NaIO}_{4}$ and concomitant silyl deprotection under the same reaction conditions resulted in the formation of $\beta$-hydroxyaldehyde 173. This common precursor was transformed via enal 174 into an acyl chloride 175 through sequential Pinnick oxidation, acetate protection and nucleophilic substitution with oxalyl chloride/DMF. Intermediates 173 and 174 underwent formal [3+3] cycloadditions with 4 -hydroxy- $2 \mathrm{H}$-pyran-2-one derivatives and promotors like piperidinium acetate or phosphoric acid derivative 176. Chemo- and diastereoselective HAT reductions under Shenvi's conditions in the presence of labile pyrone moiety yielded natural products arisugacin $\mathrm{F}(\mathbf{1 6 0})$, phenylpyropene $C$ (164) and pyripyropene E (161). Crude unsaturated acyl chloride $\mathbf{1 7 5}$ underwent Friedel-Crafts acylation in the presence of $\mathrm{BF}_{3} \cdot \mathrm{Et}_{2} \mathrm{O}$ and after Luche reduction and concomitant cyclization yielded phenylpyropene $\mathrm{F}$ (165).

The remaining four diterpene meroterpenoids were constructed from butenolide 177, which itself was forged from sclareol (169) via peracryloylation, ring-closing metathesis with Grubbs second-generation catalyst and $\mathrm{NaH}-$ $\mathrm{CO}_{3}$ mediated elimination (Scheme 18). Exocyclic double bond participated in a high-yielding and diastereoselective intramolecular Giese HAT coupling and thus formed lactone $\mathbf{1 7 8}$ was treated with $\mathrm{LiI}$ and 2,6-lutidine to arrive at carboxylic acid $\mathbf{1 7 9}$. The acid was the optimal substrate in the synthetic sequence for the modified enzymatic hydroxylation conditions on a gram scale. The formation of a Barton ester from hydroxylated carboxylic acid $\mathbf{1 8 0}$ was followed by decarboxylation and the resulting primary radical was trapped with iodoform to give primary iodide 181. On the one hand, primary iodide 181 was used in Weix nickel-catalyzed $\mathrm{sp}^{3}-\mathrm{sp}^{2}$ cross electrophile coupling reactions with aryl iodides 182 and 183. Subsequent manipulations provided taondiol (162) directly and chevalone A (167) via intermediate 184. Alternatively, primary iodide $\mathbf{1 8 1}$ was taken forward and treated with $\mathrm{KO} t \mathrm{Bu}$ to promote elimination; the conjugated diene 185 then reacted in either a CAN-mediated or electrochemical SETbased formal [3+2] coupling reactions. The former conditions gave decaturin $\mathrm{E}$ (166) directly. Synthesis of stypodiol (163) was completed with diastereoselective HAT reduction of 186 to give 187 and subsequent $\mathrm{BBr}_{3}$ demethylation.

\section{14. Sarlah's Total Synthesis of (-)-Epolone B and $( \pm)$-Dehydroxypycnidione}

The Sarlah group's interest in hetero-Diels-Alder reactions and meroterpenoids culminated in biomimetic and modular total syntheses of two naturally occurring tropolones; (-)-epolone B (188) and ( \pm )-dehydroxypycnidione (189) (Scheme 20). ${ }^{31}$ Both compounds share a common 11-membered core but differ in the number of attached tropolone moieties. It was envisioned that these two compounds could be prepared through the union of a tropolone-derived ortho-quinone methide and a-humulene (12) (or its 10-hydroxy derivative 193). The latter was prepared in an enantioselective fashion in five steps, starting from commercially available chiral pool (-)-kobusone (190) (Scheme 19). Diastereoselective $\alpha$-hydroxylation at the sterically more accessible position, followed by silyl protection and Wittig olefination provided an exocyclic olefin 191. Shenvi's HAT conditions (cobalt catalyst 192 and phenylsilane) for catalytic olefin isomerization induced a retrocycloisomerization reaction, which opened up the four-memebered ring in $\mathbf{1 9 1} .^{32}$ Finally, stereospecific rhenium-catalyzed epoxide deoxygenation developed by Takai's group furnished 10-hydroxyhumulene (193). ${ }^{33}$

Next, synthesis of tropolone-derived ortho-quinone methide precursors was pursued. It commenced with O-alkylation of 1,3-cyclopentadione (194). This transformation was achieved with paraformaldehyde and a mixture of allylic alcohols (195) in the presence of TMSCl. Vinyl chloride 196 was converted into tricycle 197 via photochemical [2+2] cycloaddition under UV irradiation with 5:1 diastereoselectivity. Out of all tested oxidation conditions only a one pot $\alpha$-iodination/Kornblum oxidation protocol $^{34}$ allowed for a selective oxidation of the a-position in the presence of a labile tertiary chloride moiety. While treatment of hydroxyenone 198 with boron trifluoride etherate yielded the expected de Mayo product 199, fragmentation of methylated derivative 200 with Lewis acids proved to be more challenging. Ulimately, this challenge was solved with the discovery of a novel photochemical fragmentation, uniquely suited for this purpose, which resulted in formation of methylated tropolone 201 .

With all cycloaddition partners in hand, reactivity of both tropolone-derived ortho-quinone methide precursors 199 and 201 was tested in hetero-Diels-Alder reactions with humulenes. Ortho-quinone methide 202, derived from the methyl protected precursor 201, was found to efficiently react with -humulene (12) as a coupling partner, giving rise to monocycloadduct 203. Due to the established superior biological activities of biscycloadducts, a second cycloaddition was attempted. Resubjecting monocycloadduct 203 to the same reaction conditions gave penultimate biscycloadduct 204. Final deprotection with sodium hydroxide completed the first total synthesis of ( \pm )-dehydroxypicnidione (189). Subsequently, the ability of 10-hydroxyhumulene (193) to react as a

Petrovčič et al.: Recent Chemical Methodology Advances in the ... 
<smiles>C=C1C(=O)C=C(CC)C(C)C1C</smiles>

201
202

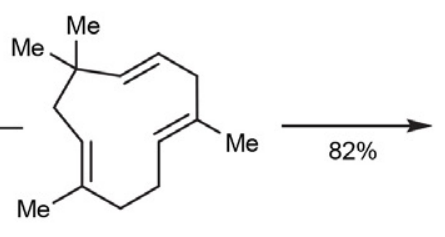

$\alpha$-humulene (12)<smiles></smiles>

203

198, $\mu \mathrm{W} \downarrow 13 \%, 1: 1 d r$<smiles>Cc1cc(=O)c(O)cc2c1C[C@H]1CC(C)(C)C=CCC(C)(C)c3cc(O)c(=O)cc(C)c3C[C@@H](C(C)C)CC[C@]1(C)O2</smiles>

( \pm )-dehydroxypycnidione (189)
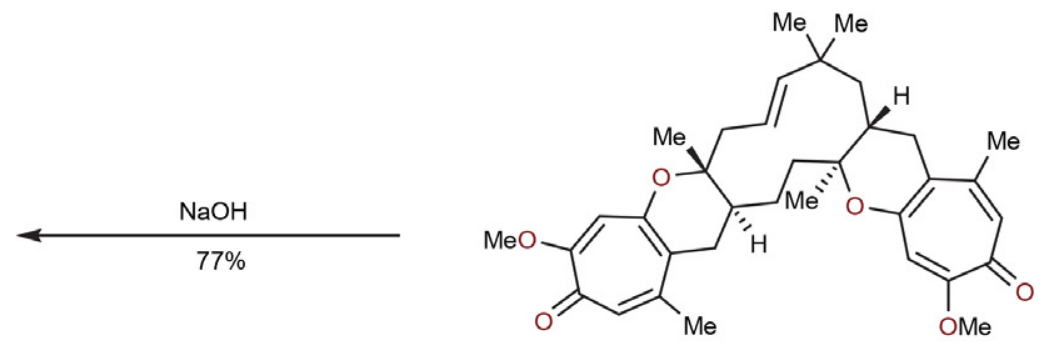

204

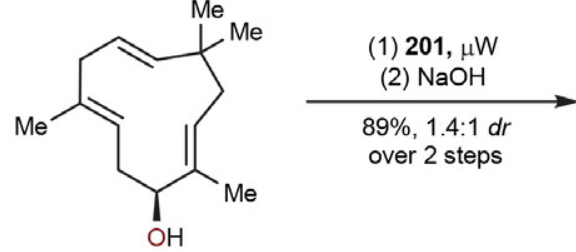

10-hydroxyhumulene (193)

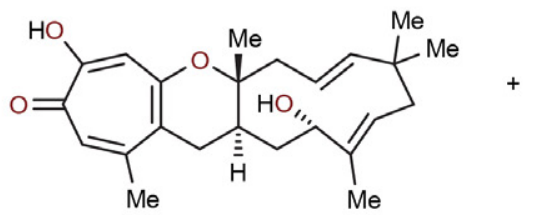

(+)-isoepolone B (205)<smiles>CC(=CCC(C)(C)C=CC[C@]1(C)Oc2cc(O)c(=O)cc(C)c2C[C@H]1C)CO</smiles>

(-)-epolone B (188)

Scheme 20: Sarlah's biomimetic total syntheses of ( \pm )-dehydroxypicnidione 189 and (-)-epolone B (188)

dienophile was explored. Ortho-quinone methide precursor 201 again proved to be superior. Under optimized conditions, a 1.4:1 mixture of diastereomeric adducts was formed. Quantitative $\mathrm{NaOH}$ deprotection of both diasteroisomers revealed (+)-isoepolone B (205) and (-)-epolone $B(\mathbf{1 8 8})$ as major and minor diastereoisomer respectively. Notably, the second cycloaddition with both deprotected diastereoisomers was attempted, but gave exclusive diastereoselectivity to unnatural bistropolones; this selectivity was further supported with computational modeling. Ultimately, the culmination of these synthetic studies have suggested alternative biosynthetic routes for these compounds in addition to the stereochemical revision of several members.

\section{Conclusion}

Having reviewed some of the most elegant meroterpenoid syntheses from the past five years a few general observations are apparent. Polyene cyclizations and (formal) cycloadditions are still prevalent chemical tools for the construction of meroterpenoid cores. The development of suitable reaction conditions and introduction of novel polyene cyclization terminating groups were crucial for the successful completion of several showcased syntheses. Reactivity of various ortho-quinone methides with naturally occurring dienophiles like $\alpha$-humulene and caryophyllene was thoroughly studied. One can observe a slow and subtle paradigm shift from more traditional polar disconnections to complementary radical-based disconnections. Certain admirable coupling name reactions (e.g. Suzuki coupling) were pushed to their limits as new types of coupling partners were explored. Progress was made on rather obscure asymmetric ketene trapping reactions as well as on highly sought-after $\mathrm{C}-\mathrm{H}$ functionalization reactions. On a similar note, challenging undirected $\mathrm{C}-\mathrm{H}$ oxidations were achieved with chemoenzymatic methods, which are finding their place among chemical methods by demonstrating high complementarity. To conclude, structural diversity and complexity of meroterpenoids will undoubtably keep inspiring chemists to develop new chemical tools for future total syntheses. 


\section{References}

1. R. Geris, T. J. Simpson, Nat. Prod. Rep. 2009, 26, 1063-1094. DOI:10.1039/b820413f

2. Y. Matsuda, I. Abe, Nat. Prod. Rep. 2016, 33, 26-53. DOI:10.1039/C5NP00090D

3. A. El-Demerdash, D. Kumla, A. Kijjoa, Mar. Drugs 2020, 18, 317. DOI:10.3390/md18060317

4. F. A. Macías, C. Carrera, J. C. G. Galindo, Chem. Rev. 2014, 114, 2717-2732. DOI:10.1021/cr300048m

5. L. Murray, S. McKinnie, B. Moore, J. George, Nat. Prod. Rep. 2020, 37, 1334-1366. DOI:10.1039/D0NP00018C

6. T. Sunazuka, S. Ōmura, Chem. Rev. 2005, 105, 4559-4580. DOI: $10.1021 /$ cr040628i

7. M. Gordaliza, Mar. Drugs 2012, 10, 358-402. DOI: $10.3390 / \mathrm{md} 10020358$

8. J. A. Richard, European J. Org. Chem. 2014, 2014, 273-299. DOI:10.1002/ejoc.201300815

9. H. C. Lam, J. T. J. Spence, J. H. George, Angew. Chem. Int. Ed. 2016, 55, 10368-10371. DOI:10.1002/anie.201606091

10. L. M. Chapman, J. C. Beck, L. Wu, S. E. Reisman, J. Am. Chem. Soc. 2016, 138, 9803-9806. DOI:10.1021/jacs.6b07229

11. C. G. Newton, D. N. Tran, M. D. Wodrich, N. Cramer, Angew. Chem. Int. Ed. 2017, 56, 13776-13780.

DOI:10.1002/anie.201708333

12. C. P. Ting, G. Xu, X. Zeng, T. J. Maimone, J. Am. Chem. Soc. 2016, 138, 14868-14871. DOI:10.1021/jacs.6b10397

13. C. P. Ting, T. J. Maimone, J. Am. Chem. Soc. 2015, 137, 1051610519. DOI:10.1021/jacs.5b06939

14. M. Elkin, S. M. Szewczyk, A. C. Scruse, T. R. Newhouse, J. Am. Chem. Soc. 2017, 139, 1790-1793.

DOI: $10.1021 /$ jacs.6b12914

15. G. Xu, M. Elkin, D. J. Tantillo, T. R. Newhouse, T. J. Maimone, Angew. Chem. Int. Ed. 2017, 56, 12498-12502.

DOI:10.1002/anie.201705654

16. H. Shigehisa, T. Aoki, S. Yamaguchi, N. Shimizu, K. Hiroya, J. Am. Chem. Soc. 2013, 135, 10306-10309.

DOI: $10.1021 / \mathrm{ja} 405219 \mathrm{f}$

17. B. Gaspar, E. M. Carreira, Angew. Chem. Int. Ed. 2008, 47, 5758-5760. DOI:10.1002/anie.200801760

18. R. Wildermuth, K. Speck, F. L. Haut, P. Mayer, B. Karge, M. Brönstrup, T. Magauer, Nat. Commun. 2017, 8, 1-9.
19. K. Speck, R. Wildermuth, T. Magauer, Angew. Chem. Int. Ed. 2016, 55, 14131-14135. DOI:10.1002/anie.201608040

20. W. Yu, P. Hjerrild, K. M. Jacobsen, H. N. Tobiesen, L. Clemmensen, T. B. Poulsen, Angew. Chem. Int. Ed. 2018, 57, 98059809. DOI:10.1002/anie.201805580

21. W. Yu, P. Hjerrild, J. Overgaard, T. B. Poulsen, Angew. Chem. Int. Ed. 2016, 55, 8294-8298. DOI:10.1002/anie.201602476

22. J. M. Winter, A. L. Jansma, T. M. Handel, B. S. Moore, Angew. Chem. Int. Ed. 2009, 48, 767-770.

DOI:10.1002/anie.200805140

23. P. J. Li, G. Dräger, A. Kirschning, Org. Lett. 2019, 21, 9981001. DOI:10.1021/acs.orglett.8b04003

24. Z. Powers, A. Scharf, A. Cheng, F. Yang, M. Himmelbauer, T. Mitsuhashi, L. Barra, Y. Taniguchi, T. Kikuchi, M. Fujita, I. Abe, J. A. Porco, Angew. Chem. Int. Ed. 2019, 58, 1614116146. DOI:10.1002/anie.201910710

25. J. Li, F. Li, E. King-Smith, H. Renata, Nat. Chem. 2020, 12, 173-179. DOI:10.1038/s41557-019-0407-6

26. M. Handa, T. Sunazuka, A. Sugawara, Y. Harigaya, K. Otugro, S. Ōmura, J. Antibiot. (Tokyo). 2003, 56, 730-733.

DOI:10.7164/antibiotics.56.730

27. A. B. Smith, T. Kinsho, T. Sunazuka, S. Ōmura, Tetrahedron Lett. 1996, 37, 6461-6464.

DOI:10.1016/0040-4039(96)01439-6

28. D. H. Dethe, S. Mahapatra, S. K. Sau, Org. Lett. 2018, 20, 2766-2769. DOI:10.1021/acs.orglett.8b00997

29. A. S. Kumanireng, T. Kato, Y. Kitahara, Chem. Lett. 1973, 2 , 1045-1047. DOI:10.1246/cl.1973.1045

30. A. Abad, C. Agulló, M. Arnó, A. C. Cuñat, B. Meseguer, R. J. Zaragozá, J. Org. Chem. 1998, 63, 5100-5106.

DOI:10.1021/jo980311g

31. C. Y. Bemis, C. N. Ungarean, A. S. Shved, C. S. Jamieson, T. Hwang, K. S. Lee, K. N. Houk, D. Sarlah, J. Am. Chem. Soc. 2021, 143, 6006-6017. DOI:10.1021/jacs.1c02150

32. S. W. M. Crossley, F. Barabé, R. A. Shenvi, J. Am. Chem. Soc. 2014, 136, 16788-16791. DOI:10.1021/ja5105602

33. T. Nakagiri, M. Murai, K. Takai, Org. Lett. 2015, 17, 33463349. DOI:10.1021/acs.orglett.5b01583

34. Y. F. Liang, X. Li, X. Wang, M. Zou, C. Tang, Y. Liang, S. Song, N. Jiao, J. Am. Chem. Soc. 2016, 138, 12271-12277.

DOI:10.1021/jacs.6b07269

\section{Povzetek}

Strukturna raznolikost meroterpenoidov, ki izvira iz kombinacije biosinteznih poti, buri domišljijo sinteznih kemikov in jih spodbuja, da konstanto izpopolnjujejo svojo retrosintezno logiko. Literaturni pregled nedavnih totalnih sintez meroterpenoidov razkriva izjemen napredek v razvoju kemijske metodologije. Namen tega preglednega članka je prikaz najbolj inovativnih sintez in sinteznih študij na področju kemije meroterpenoidov v zadnjih petih letih.

Except when otherwise noted, articles in this journal are published under the terms and conditions of the Creative Commons Attribution 4.0 International License 